WHAT TO EXPECT? EXAMINING THE ROLE OF PRE-DEPARTURE CULTURAL ORIENTATIONS

\author{
By
}

Ashley Kom, BA Saint Mary's University, 2007

\author{
A Major Research Paper \\ presented to Ryerson University \\ in partial fulfillment of the requirements for the degree of \\ Master of Arts \\ in the Program of \\ Immigration and Settlement Studies
}

Toronto, Ontario, Canada, 2009

(C) Ashley Korn 2009 


\section{Author's Declaration}

I hereby declare that I am the sole author of this major research paper.

I authorize Ryerson University to lend this paper to other institutions or individuals for the purpose of scholarly research.

Signature

I further authorize Ryerson University to reproduce this paper by photocopying or by other means, in total or in part, at the request of other institutions or individuals for the purpose of scholarly research.

Signature 


\title{
WHAT TO EXPECT? EXAMINING THE ROLE OF PRE-DEPARTURE CULTURAL ORIENTATIONS
}

\author{
Ashley Korn \\ Master of Arts, 2009 \\ Immigration and Settlement Studies \\ Ryerson University
}

\begin{abstract}
Providing relevant pre-migration information for newcomers to Canada can have many potential benefits, however there is a gap in understanding the implications of pre-departure cultural orientations (P-DCO) on refugee resettlement. This research focuses on the unique resettlement experiences of privately sponsored refuges entering Canada through the Student Refugee Program (SRP). The purpose of this research is to understand how P-DCO impacts the resettlement of SRP participants and identify the effectiveness of such programs. The study uses the theoretical lens of cultural and social capital to understand the role of P-DCO in the migration and resettlement of SRP participants. Individual interviews were conducted with 6 SRP participants, as well as a key informant interview with the SRP Senior Program Officer. This exploratory study contributes to an enhanced understanding of the effectiveness of P-DCO for refugees in their resettlement and advocates further research for other immigrant categories.
\end{abstract}

Key Words: Refugee migration; Refugee resettlement; Canada; Pre-departure Cultural Orientation 


\section{Acknowledgements}

I would like to express my sincere gratitude to my research supervisor, Dr. Grace-Edward Galabuzi for supporting me in pursuing this research study, and thank him for his guidance, and academic advice throughout the year. I also deeply appreciate the input, support, and guidance of Dr. Francis Hare as my second reader, professor, and faculty advisor.

I am extremely grateful to all of the people who voluntarily participated in this study, sharing their stories, knowledge, and insight about their experiences. This study could not exist without their generous commitment of time and energy to sit and talk with me.

In addition, I would like to thank World University Service of Canada (WUSC), Student Refugee Program (SRP) staff, Lynne Leblanc and Asni Mekonnen for their contribution, assistance, and support of this study. As well, I owe much gratitude to members of the Ryerson WUSC local committee, Mary Pam Vincer and Jackie Strecker for encouraging me to do this research and providing me with essential information, and feedback.

Finally, I would like to acknowledge and express my loving thanks to my partner, Adam Lariviere for his commitment of time and effort, providing countless hours of editing and input to this research. His constant encouragement and unconditional support reinforced belief in my ability to complete this research. I would also like to thank my family for their continued support and guidance in my life path. 
Introduction 1

$\begin{array}{ll}\text { Literature Review } & 4\end{array}$

$\begin{array}{ll}\text { Theoretical Framework } & 18\end{array}$

Methods and Data Analysis $\quad 22$

$\begin{array}{ll}\text { Findings } & 28\end{array}$

$\begin{array}{ll}\text { Discussion and Recommendations } & 61\end{array}$

Areas For Future Research $\quad 66$

$\begin{array}{ll}\text { Conclusion } & 67\end{array}$

$\begin{array}{ll}\text { References } & 74\end{array}$

List of Tables

$1 \sim$ Cultural capital categories \& cultural competencies valuable in SRP resettlement 20

$2 \sim$ Cultural capital components of IOM and WUSC P-DCO 29

\section{List of Appendices}

$\begin{array}{ll}\text { Appendix A } & 70\end{array}$

Appendix B $\quad 71$

Appendix C $\quad 72$ 


\section{List of Acronyms}

CCR - Canadian Council for Refugees

COA - Cultural Orientation Abroad

CIC - Citizenship and Immigration Canada

GAR - Government Assisted Refugees

IOM - International Organization for Migration

ISS - Interpretive Social Science

P-DCO - Pre-Departure Cultural Orientation

PSR - Privately Sponsored Refugees

SRP - Student Refugee Program

UNHCR - United Nations High Commissioner for Refugees

WUSC - World University Services of Canada 


\section{Introduction}

The Canadian government has often been considered a leader on the international stage in regards to its post World War II immigration policies pertaining to displaced persons and refuges $(\mathrm{Li}, 2003)$. From the $1960^{\prime}$ 's to present the Canadian govemment has worked towards maintaining its international legal obligation and humanitarian tradition by taking in a prescribed number of refugees each year in relation to the other categories of immigrants $(\mathrm{Li}$, 2003). In 2008, according to Citizenship and Immigration Canada (CIC), 21,860 refugees entered the country as part of the total number of 247,243 immigrants to Canada.

Within the broad category encompassing refugees, there are variations as to how refugees enter Canada, either as privately sponsored refugees (PSR), government assisted refugees (GAR), or refugee claimants. Reasons that refugees leave their country vary, whether it is on economic, political or social grounds (Li, 2003). Refugee migration is largely on an involuntary basis and often permanent. In the context of refugee migration, it is generally motivated by push, rather than pull factors of migration theory. Significant challenges may be experienced in the intercultural transition since there is often little preparation prior to departure.

Although the Canadian govermment accepts a significant number of refugees each year, criticism within Canada from a myriad of organizations and academic disciplines, suggests the unique resettlement needs of refugees are unmet through current settlement service structure (Beiser, 2006; George, 2002; Stewart et al 2008; Wilkinson, 2002; Yu, Ouellet \& Warmington, 2007). However, to limit the resettlement challenges faced by refugees, the Canadian government provides a Cultural Orientation Abroad (COA) prior to departure for GAR, and some PSR, among other migrant groups. The COA is an initiative of the Canadian Federal government, which was implemented in 1998, and is delivered overseas by the 
International Organization for Migration (IOM) (CIC, 2005a). The COA attempts to provide recipients with conceptual ideas of what to expect when they arrive in Canada in regards to resettlement challenges.

There is a need for research to investigate the presence and relevance of pre-departure preparation and knowledge for newcomers. The information gathered through research is essential in exploring how appropriate pre-migration preparation may function to facilitate resettlement and integration for newcomers to Canada. In addressing this gap in the research, I have focused on participants of the Student Refugee Program (SRP), a program run through the World University Services of Canada (WUSC), who receive the COA, along with other pre-departure preparation. In doing so, I examine the role of the pre-departure cultural orientation (P-DCO) in their transition to Canada. Therefore my research is framed by questions that consider the experiences of the SRP participants in relation to the P-DCO they received. Accordingly, the study focuses on the following questions: (1) What is the nature of the P-DCO received by the SRP participants? (2) Is the content provided in the P-DCO to students in the SRP relevant to their experiences once in Canada? (3) Does the P-DCO adequately prepare the participants for what they experiences when they arrive in Canada? (4) Are amendments to the P-DCO material required to better prepare SRP participants for their anticipated transition to Canada?

\section{Student Refugee Program Overview}

The SRP is the only refugee sponsorship program in Canada that links resettlement and post-secondary education. Since 1978 WUSC has worked with the Canadian and Quebec governments, partner organizations in refugee camps, WUSC local committee student volunteers, and staff and faculty at Canadian universities to develop opportunities for refugee youth to attend Canadian universities. At present, the SRP has sponsored upwards of 900 
refugee students to receive a Canadian post-secondary education, while resettling in Canada (WUSC, 2007a).

WUSC local committees are comprised of student volunteers who work with their universities to sponsor a student refugee, often for a one-year period. The local committees lobby the school administration and raise funds to support a sponsored student. "The sponsorship includes tuition, school supplies, room and board and living expenses. In addition to financial support, volunteers offer a great deal of social support" (WUSC, 2007a, p. 4).

At the other end of the sponsorship process, refugee youth looking for opportunities to continue their education and receive resettlement seek the SRP, and apply through partner organizations to compete for the limited spots available. The SRP currently operates in Kenya, at the Dadaab and Kakuma refugee camps. ${ }^{1}$ The application process takes approximately one full year. The eligibility criteria for the SRP are: Applicants must be a recognized refugee by the United Nations High Commission for Refugees (UNHCR), between the ages of $17-25^{2}$, and have a high school diploma. As well, the applicant's English proficiency must meet the requirements of the Test of English as a Foreign Language (TOEFL) for university acceptance. The applicants have several interviews during the application process, with WUSC, their partner organizations, and the Canadian High Commission. These interviews assess the applicants' eligibility criteria for acceptance into the program. Finally, the SRP participants must pass the mandatory security and health check required by the Canadian government of all immigrants to Canada. Upon acceptance into the program, the students receive a one-year English as a Second Language (ESL)/TOEFL

\footnotetext{
${ }^{1}$ Since the development of the SRP, the program has operated and sponsored students from other refugee camps in Africa, as well as refugee camps in Thailand.

${ }^{2}$ The SRP has changed the age requirements over the years and I am referring to the current eligibility age requirement for the program.
} 
preparation course, where they improve their English proficiency and learn research skills and computer skills to prepare them for university.

Prior to departure the SRP participants are made aware of the university they will be attending, and often receive information from their sponsoring local committee about the university and city or town to which they will be resettling. Within the weeks and months prior to departure, the SRP participants are given a COA by the IOM; a copy of the Predeparture Guide for WUSC Sponsored Students: Almost Everything You Wanted to Know about Living and Learning in Canada, but were afraid to ask, often in connection with a debriefing session held by a WUSC representative at the refugee camp; and some SRP participants have been fortunate to receive orientations by visiting Canadians and Canadian students at the refugee camps. It is the combination of these pre-departure preparation methods that I will be examining as the P-DCO for participants of the SRP.

\section{Literature Review}

There is little academic research available that directly addresses pre-departure programming for immigrants and refugees anywhere in the world. Therefore, for the purpose of this literature review, I will draw on a diverse body of literature. I attempt to cover the significant themes, which establish the base of the issue I will explore. Given that there are three categories of refugees that enter Canada, to narrow the focus, this literature review is based on convention refugees, omitting the cases of refugee claimants. The literature encompassed in this review includes a multitude of experiences from various ethno-racial groups and differing pre and post-migration experiences. Research illustrates how premigration experiences, such as expectations built through transnational ties (Horst, 2006; Simich, Hamilton \& Baya, 2006) and other lived experiences prior to migration (McLean, 
Friesen \& Hyndman, 2006; Suzuki, 2005), impact and influence the outcome of resettlement for refugees once in Canada. It is suggested that the development and use of social networks and cultural capital prior to migration, such as family, friends, and socio-cultural knowledge, are believed to improve an immigrant or refugee's ability to settle into the receiving society (McLean, Friesen and Hyndman, 2006; Simich, Beiser \& Mawani, 2003; Suzuki, 2005; Ward, Bochner, and Furnham, 2003). Therefore, the notion of social and cultural capital (Bourdieu, 1973, 1986; Portes, 1998) can be employed to emphasize the importance and relevance of predeparture programming for students in the $\mathrm{SRP}$, as the implications can potentially increase their social knowledge and networking prior to migration.

In addition, I focus on the intersectionality of issues that refugees face during their resettlement process such as: Accessing settlement services appropriate for their specific needs when arriving in the country of resettlement (George, 2002; Stewart et al, 2008; Yu, Ouellet \& Warmington, 2007); language acquisition (Beiser \& Hou, 2001; Biles, 2008); labour market experiences (Lamba, 2003; Valtonen, 1999; Wilkinson, 2008; Yu, Ouellet \& Warmington, 2007); and housing (Murdie, 2003; Yu, Ouellet \& Warmington, 2007). In conjunction with the resettlement issues faced by refugees in general, I will tie in literature, where possible, that addresses experiences of refugee youth (Kilbride et al, 2001), as many of the SRP participants would be considered youth during the time of their resettlement.

I explore the literature surrounding the importance of pre-departure programming for international students (Jackson, 2004; Martin, 1989; Ramsey, 2007; Ward, Bochner, and Furnham, 2003; Ying, 2002), as it applies to the experiences of the participants in the SRP. By examining dialogue in the areas of refugee resettlement and the experiences of international students, I will situate the importance of research in the field of P-DCO, especially for students in the SRP. 
Looking beyond the realm of academic literature, organizations such as the UNHCR, and the IOM, as well as CIC have published works addressing the role and need of P-DCO for immigrants and refugees. This literature encompasses both the Canadian context as well as the international context of P-DCO for immigrants and refugees.

\section{Pre-Migration Experiences, Social Capital and Developing Expectations}

Refugees that migrate to Canada are often culturally and linguistically diverse from the Canadian context. The circumstances of forced migration of refugees can have a substantive affect on their resettlement (Ward, Bochner, \& Furnham, 2003). Consequently, pre-migration experiences often coincide with resettlement and can have a significant impact on the resettlement process for refugees. Researchers in the field of psychology and refugee studies have explored the role of pre-migration experiences of refugees, and how those experiences can develop social capital, or networks, that can assist in the resettlement process (CCR, 2003; McLean, Friesen \& Hyndman, 2006; Simich, Beiser \& Mawani, 2003; Stewart et al, 2008; Suzuki, 2005). Other academics have investigated pre-migration experiences and how they can negatively impact the resettlement process through the creation of false expectations that can lead to disappointment upon arrival (Horst, 2006; Simich, Hamilton \& Baya, 2006; Stewart et al, 2008).

Social ties with family and friends prior to migration and upon arrival are important factors, which often contribute to the success of refugee resettlement (McLean, Friesen \& Hyndman, 2006). The research suggests that when refugees are resettled, but are unhappy with their access to family and friends, or others from the same ethno-racial group, they will often relocate in order to be in closer contact with their social networks (Simich, Beiser \& Mawani, 2003). Both Suzuki (2005) and McLean, Friesen \& Hyndman's (2006) research draws on the experiences of refugee groups that were resettled in a geographical region with 
people from the same ethno-racial background, and generally from the same refugee camps. Suzuki (2005) also notes that the UNHCR has begun to recognize refugees in groups and attempts to resettle them together to ensure maintenance of social connections and support during the resettlement process.

Refugees that migrate to Canada, whether through private or government sponsorship, will often receive information about what life is like in the receiving country, either through transnational ties with those who have already migrated, or through COA administered by the IOM. Having support and accurate information during the initial stages of the migration process can contribute to easing concerns and anxieties about resettlement (Stewart et al, 2008). McLean, Friesen \& Hyndman (2006) state that many GAR receive varying degrees of information prior to departure according to the context from which they are migrating. The authors found that the information received by the refugees was general and inconsistently distributed (McLean, Friesen \& Hyndman, 2006). McLean, Friesen \& Hyndman (2006) call for reform in policy to ensure that all refugees destined for Canada are able to engage in a comprehensive orientation, appropriate to refugees' needs prior to departure, and once they arrive in Canada.

Information provided by government bodies and partner organizations, the media, and transnational ties, act as networks where refugees to be resettled develop expectations of their destination culture. The development of expectations prior to migration can potentially lead to disappointment upon arrival, as the knowledge gained through transnational ties can blur the lines between what is realistic and what is fictional (Horst, 2006). Most newcomers to Canada are found to arrive with high expectations for an improved quality of life. However, often upon arrival and during resettlement, the reality of the challenges faced in the resettlement process set in, and expectations are lowered (Stewart et al, 2008). Furthermore, when 
expectations of resettlement are unmet due to significant challenges in the resettlement process, refugees can be left in distress, resulting in poor mental health (Simich, Hamilton \& Baya, 2006). Therefore, ensuring that refugees receive realistic information, so as not to develop false expectations, can help to avoid negative experiences and outcomes in the resettlement process.

\section{Refingee Resettlement Issues}

Research in the field of refugee resettlement traverse many disciplines, such as refugee studies, psychology, sociology, social work, geography, and forced migration studies.

Literature in this area also covers a diverse population, encompassing various ethno-racial groups with differing pre and post-migration experiences. This body of literature suggests that refugees face significant challenges during their resettlement, and there are varying factors that contribute to the resettlement experiences. Although my study focuses on the premigration and resettlement of Student Refugee Program (SRP) participants, issues pertaining to resettlement are not distinct from the notion of integration. What constitutes integration is debated, but for the purpose of this study I use Yu, Ouellet \& Warmington's (2007) definition as "a dynamic, multi-faceted two-way process which requires adaptation on the part of the newcomers, but also the society of destination" (2). Understanding resettlement and integration contributes to the experiences of the SRP participants' migration, and is useful in establishing a measurement to analyze the success of the Pre-Departure Cultural Orientation (P-DCO) in facilitating successful resettlement and integration of SRP participants.

\subsection{Settlement Services}

The settlement services for refugees, available in Canada, range from mainstream settlement services to ethno-specific settlement services, to refugee specific services ( $\mathrm{Yu}$, Ouellet \& Warmington, 2007). Most agencies that address initial settlement needs provide 
services for assistance in finding shelter, employment, language acquisition and basic orientation (George, 2002). Settlement services are offered by community based, not-forprofit organizations contracted by the Federal government.

It is suggested that most newcomers arriving in Canada are unaware of the institutional support services that are available to aid with their settlement needs and integration (Stewart et al, 2008). Despite the availability of settlement services upon arrival, Stewart et al (2008) note that if newcomers are not provided with knowledge about the "system" and services that are present in Canada, it will limit their likelihood of accessing the services. Having access to relevant information prior to migration about the settlement process, and future integration in Canada, can be helpful to ensure newcomers are autonomous when navigating the system (Stewart et al, 2008).

Further emphasized in the research by Stewart et al (2008), is that notions of social support and accessing services are culturally specific. Many refugee communities commonly perceive their family and friends as their support network (Stewart et al, 2008). Stewart et al (2008) suggest that it is habitual for refugees to uphold their perceptions of support, despite the reality that their support milieus have changed. Newcomers, especially refugees, often have weakened social networks and face challenges in establishing and maintaining new social networks, which can be used to facilitate settlement (Stewart et al, 2008).

In research engaging the experiences of newcomer youth and their migration and settlement, Kilbride et al (2001) discuss the challenges faced in the resettlement experience, with a focus on refugee youth's realities. The authors' findings suggest that settlement services must work to address and implement adequate programming that targets the unique needs of the youth populations. Although many of the issues addressed in the research echo that of adult newcomers, youth remain a distinct and diverse group that requires specific 
policy and programming to encourage successful resettlement and integration (Kilbride et al, 2001). Another contributing factor to accessing appropriate services for youth that arose in the authors' findings is that like adult refugees, youth are often unaware of the issues they will face during the migration and resettlement journey. Canadian culture, expectation of the education system, roles of educators, acceptable behaviour and mainstream values are areas of cultural knowledge the youth felt would have been valuable during their initial settlement (Kilbride et al, 2001).

\subsection{Language Acquisition}

Attaining language proficiency in the receiving countries' official language has been found to facilitate increased independence, development of social resources, and broaden coping strategies for refugees (Beiser \& Hou, 2001). Language acquisition is notably the most important element of resettlement in Canada, as it is imperative to finding meaningful employment and integrating into the wider community. Attending language training upon arrival can be challenging for refugees. Often other needs' such as entering directly into the labour market to secure an income, will take precedence, leaving language training to go by the way-side (Beiser \& Hou, 2001; Biles, 2008). It is suggested that if refugees are able to attend language training their career prospects and long-term integration would likely improve (Biles, 2008).

Refugee youth similarly face challenges in regards to language acquisition and proficiency. Youth culture in North America tends to have diverse dialects, and understanding the jargon and slang can prove to be difficult for newcomer youth. Similarly, developing confidence to use the language proficiency newcomer youth already have can be challenging. For those newcomer youth that have limited official language functions upon arrival, difficulties faced in their educational attainment can increase, contributing to low self-esteem 
and an increase in perceived discrimination (Kilbride et al, 2001). Compounding youth's experiences at school, is the reality of teachers reinforcing stereotypes, and the role language proficiency and accents may play, adding to the already complex settlement reality. If educators allow cultural stereotypes to impede their ability to engage with newcomer youth, it can have a significant impact on how the youth view themselves at school (Kilbride et al, 2001).

\subsection{Employment}

Another significant element in the refugee resettlement process is obtaining employment. Refugees face much of the same challenges as the larger immigrant population in Canada, such as lack of official language skills, lack of Canadian work experience and education, as well as challenges in getting recognition of their foreign credentials. Although there are similarities, refugees' situations are often more uncertain (Yu, Ouellet \& Warmington, 2007).

Yu, Ouellet \& Warmington (2007) contend that refugees struggle as they generally have low levels of formal education compared to other immigrant categories. The low levels of education can be directly linked to the low economic outcomes that refugees' often experience after resettlement. However, refugees that have higher levels of education and language proficiency are more likely to obtain employment (Wilkinson, 2008).

In addition to these factors mentioned, accessing employment is also dependent on the individual's duration of residence within Canada, the length of time that the community to which they associate has lived in the country, and the state of the economy (Valtonen, 1999). If the ethnic community of the refugee seeking employment has established ethnic enclave economies, they may be able to gain some Canadian work experience through those networks (Lamba, 2003). 
Parallel to the experiences of adult refugees, refugee youth also experience difficulty with recognition of their educational qualifications. Furthermore, ${ }^{66}$ newcomer youth face greater obstacles to employment and are far less likely than Canadian youth to have [relevant] work experience" (Kilbirde et al, 2001, p. 50). Coinciding with lack of Canadian experience, refugee youth will often have less family connections and networks into the Canadian working world, further reducing opportunities for employment. At the same time, language proficiency can also be a significant factor for refugee youth in accessing employment opportunities (Kilbride et al, 2001).

\subsection{Housing}

In the discipline of geography there is a fair amount of research regarding urban and rural settlement patterns and segregation of immigrants and racialized groups in housing, but there is little available that directly addresses refugee populations. The discipline of refugee studies has done some research in this area as well. Research suggests that refugees are in precarious situations when it comes to finding temporary or permanent housing. Refugees generally have low income and are unable to afford the high rent that is a reality in many of the major cities where they commonly settle (Yu, Ouellet \& Warmington, 2007). As well, as cited by $\mathrm{Yu}$, Ouellet \& Warmington (2007), surveys distributed in British Columbia found that a majority of refugees spent more than half of their income on rent. As a result of the high cost of rent in many Canadian cities, refugees are found to 'double-up', where multiple families and friends may reside in one unit in order to ensure affordability (Statistics Canada: LSIC 2005, 24-25, cited in: McLean, Friesen and Hyndman, 2006).

Accessing affordable and suitable housing can be determined by various factors, such as established social networks present upon arrival, access to employment, the number of people that need to be housed in a unit, as well as discrimination within the housing market 
(Murdie, 2003). The research finds that refugee groups, for example those from Somalia, are presented with significant challenges when accessing adequate housing, as they do not have an established community in Canada compared to other migrant groups. As well, they are a racialized group and are further stigmatized by their migration status. Refugees generally do not have access to references and do not have a credit history, which are commonly required to apply for housing (Murdie, 2003).

\section{International Students}

Although international students are considered to be temporary migrants, their experiences attending academic institutions, and origination from diverse socio-cultural contexts, offers perspective on the realities of students in the Student Refugee Program (SRP). The literature base pertaining to international students lies in the disciplines of education studies, intercultural or cross-cultural studies and linguistics. Ward, Bochner, \& Furnham (2003) have written extensively on the experiences of international students, engaging in the notions of friendship and networks, and academic intercultural interaction. Coinciding with the above mentioned research, I examine two studies which focus on the experiences of Asian students from Hong Kong and Taiwan attending American schools (Jackson, 2004; Ying, 2002); another study that presents the experiences of an international student body participating in a mentorship program in New Zealand (Ramsey, Ramsey \& Mason, 2007); and research done on a pre-departure program developed for students who are going to study abroad from a university in the United States (Martin, 1989).

Research established by Ward, Bochner, \& Furnham (2003) suggests that international students of diverse ethno-racial backgrounds from that of the receiving society are found to have a difficult time establishing friendships with those in the receiving group. The challenge of friendship and network building for international students is often influenced by stereotypes 
established at both ends of the spectrum within an academic structure. These intergroup stereotypes often lead to perceived discrimination by international students, emphasizing the potential for isolation (Ward, Bochner, \& Furnham, 2003).

Ward, Bochner, \& Furnham (2003) suggest that international students gamer substantial challenges relating to academic pressures and financial barriers. However, many of these challenges are reified in the context of young students attending academic institutions. None-the-less, it is apparent in the research that international students must endure, not only academic learning, but also culture-learning. International students must leam the culture of the classroom, adapting to the teaching style of the academic institution, and more specifically their professors (Ward, Bochner, \& Furnham, 2003). The multi-layered intercultural interaction, which emphasizes the challenges faced by these sojourners are found to be most prevalent during the initial stages of the transitional processes and subside as they adjust to their new surroundings (Ward, Bochner, \& Furnham, 2003).

Ramsey et al (2007) provides a brief analysis of the perception toward international students by the faculty and students at a university in the receiving society. The authors suggest that students at the receiving university may feel, in an academic situation, such as group work, that international students may need to be carried. Therefore some students may avoid working in class with international students (Ramsey et al, 2007). This can contribute to international students feeling isolated, as they may avoid interactions with people from different cultural and language groups than their own, to avoid being alienated. The research highlights that some university faculty believe that international students present new demands on their teaching, as they may require more time and assistance to adjust into the new academic setting (Ramsey et al, 2007). 
Ward, Bochner, \& Furnham (2003) state that upon arrival international students do, to varying degrees, struggle with adjustment depending on social factors prior to departure. Although, homesickness and culture shock are common, these feelings can be exacerbated by cultural differences such as a new diet and food selection, along with differing health beliefs (Jackson, 2004). Furthermore, displays of affection and social norms of personal space during social interaction can create feelings of unease, as these are culturally specific actions (Jackson, 2004). If students are not appropriately prepared for their intercultural interactions, it can lead to awkward moments and unsettling encounters, which may increase the likelihood of being withdrawn in their new environment.

Prior to departure, many international students have concerns of the unknown, coupled with excitement about their journey. It is important that international students are well prepared for the culture shock they are likely to encounter upon arrival in a new place (Martin, 1989). The level of intercultural training that the students receive should be relative to the level of socio-cultural difference they will experience; depending on what country they are originating from and studying in. Martin's (1989) study suggests that, prior to departure, students must be intellectually, behaviourally and emotionally prepared, so they are able to handle studying in a new and different environment. Encompassing skills such as flexibility, tolerance for uncertainty, self-confidence, independence and the ability to communicate crossculturally will enable the students to settle and integrate more effectively into their new environment (Martin, 1989). If students are adequately prepared with knowledge of the place they are going to study, and the skills they need for intercultural interaction and communication, they will be more likely to form intercultural relationships (Ying, 2002). 


\section{Pre-departure Information}

\subsection{International Organizations}

The United Nations High Commissioner for Refugees (UNHCR) produced a document in 2004 titled, Supporting Next Steps in Integration Initiatives: An Inventory of Opportunities and Needs in the Integration of Resettled Refugees. In it, the UNHCR establishes that "refugees should have as much information as possible of what awaits them upon arrival in the resettlement country [...] concerning the language, culture, climate and population of the country" (20) as a minimum. Pre-departure orientation sessions are a useful tool, often balanced with post-arrival orientations for refugees, to best prepare them for the resettlement process (UNHCR, 2004). As well, it is imperative for countries that have implemented predeparture orientations to ensure that the information that is provided to refugees be up-to-date and relevant, eschewing the development of any false expectations (UNHCR, 2004).

The International Organization for Migration (IOM) (2004) states that, "refugees accepted for resettlement $[\ldots]$ often come straight out of camps and have little, if any, knowledge of the societal and economic practices of a modern, capitalistic country" (1). Refugees may also have developed unrealistic, and commonly inaccurate conceptions and expectations of what their lives will be like in the country of resettlement. If no attempt is made to address pre-migration expectations through Pre-Departure Cultural Orientations ( $\mathrm{P}$ DCO), it could cause superfluous stress for the refugee upon arrival; in turn, creating pressure on settlement services within the country of migration (IOM, 2004).

The IOM (2004) also contends that implementing P-DCO can alleviate pre-migration anxieties refugees may have, by providing realistic information of what awaits them in the country of resettlement. Furthermore, these orientations enable refugees to establish strategies 
in dealing with the unfamiliar, and develop "links between their country of origin and the country of destination" (IOM, 2004, p.1).

\subsection{Canadian Government}

Cultural Orientations Abroad (COA) sessions are jointly developed by Citizenship and Immigration Canada (CIC) and the IOM, and are delivered abroad by the IOM to facilitate newcomers' resettlement and integration into Canadian society. CIC (2005a) acknowledges that the IOM understands the objectives of the COA, but that there is a "lack of systematic knowledge of the orientation needs of immigrants and convention refugees from different countries and cultural groups" (3). Furthermore, CIC (2005a) states that the material used in the COA is out of date and at times only partially distributed to pre-migration migrants. CIC (2005a) contends that the COA participant's manual is under translated and therefore less accessible to the diverse populations it has been developed for. CIC (2005a) also reports that although facilitators are well trained in the facilitation approach employed by $\mathrm{CIC}$ and the IOM, those who implement the COA have been found to lack in their direct knowledge of Canada. Additionally, the time allotted to complete the COA is insufficient (CIC, 2005a). Although CIC (2005a) recognizes the many flaws in the COA delivery approach, they noted that the content of the COA is generally appropriate for convention refugees, perhaps suggesting that their specific pre-migration needs are less valued, compared to that of other immigrant groups.

Another CIC (2005b) report that investigates Canada's membership in the IOM contends that providing immigrants and refugees with the COA, implemented by the $10 \mathrm{M}$, has lead to a reduction in the use of in-Canada settlement services when they arrive in the country. Consequently, implementing pre-departure orientations for newcomers can be viewed as a preventative measure, taking the pressure off of overwhelmed settlement services in Canada. 
Although CIC acknowledges the value of the COA program, as it is advantageous for the participants to expand their knowledge of settlement experiences prior to arrival, it is apparent that $\mathrm{CIC}$ is aware of the need for program reform. By investing in this anticipatory step in the migration process, pre-migration cultural training can potentially contribute to the long-term success of settlement and integration.

\section{Theoretical framework}

The theoretical frameworks that I have engaged to guide this research initiative are useful as they contribute to, and strengthen the analysis of this study. The theories of cultural and social capital as discussed by Bourdieu $(1973,1986)$, although distinct from one another, work together to demonstrate the need for the development of culturally specific knowledge and networks to enable meaningful participation in a cultural society. Cultural capital encapsulates the cultural competencies needed to successfully navigate within a social or cultural group (Bourdieu, 1973, 1986). In the traditional use of cultural capital theory, it is argued that given one's socialization in a particular social class, upward mobility from a social class can be restricted if an individual is without the cultural knowledge and symbols that characterize a social class (Bourdieu, 1973; Torres, 2009). Social capital considers the social networks an individual has membership in, providing access to resources and supports within a social context (Bourdieu, 1973, 1986; Kunz, 2005).

The research requires both theories to provide a lens for examining the findings, however I rely more on the dimensions of cultural capital as it gives voice to the need for systematic pre-departure cultural knowledge in order to navigate and succeed in the Canadian socio-cultural system. Through developing the cultural competencies needed to successfully navigate the Canadian social systems, newcomers can potentially avoid challenges faced 
during settlement and integration. The notion of social capital, although a less significant factor in the discussion of Pre-Departure Cultural Orientations (P-DCO), is necessary insofar as it demonstrates the need for network building in order to create a domain to further increase, engage and utilize cultural capital. While these theories are based on analysis of social class, I am using them slightly outside of the conventional application to illustrate the need for cultural training. It is important that the cultural training enables transmission of Canadian cultural competencies to refugees so they have the tools to navigate and participate in Canadian society during resettlement.

Bourdieu (1973) uses the terms codes and tools to refer to the linguistic and cultural competencies encompassed within a society's cultural capital. These competencies allow an individual to function in a social class or particular society or culture. For the purpose of this research I have established categories of what constitutes cultural capital, which coincide with the main themes in the findings. Within each category, I have identified cultural competencies required in the resettlement and integration experiences of Student Refugee Program (SRP) participants (See Table 1). Bourdieu (1973) suggests those who lack the competencies are often excluded from that social class, culture or society, as they do not possess the codes and tools to engage with it. By acquiring the necessary cultural competencies within cultural capital, SRP participants can be adequately prepared for their resettlement and integration. If an individual can engage in cultural training to gain the tools and codes to decipher and function within the culture, one can become familiar with cultural norms and ways of doing and thinking relational to the culture one wishes to participate in. Bourdieu (1973) suggests that an individual can only completely understand and succeed in a social or cultural context if they are given the appropriate socialization or 'apprenticeship'. The system or society does not teach the necessary tools or codes, but it does expect everyone to posses them in order to 
Table $1 \sim$ Cultural capital categories \& cultural competencies valuable in SRP resettlement

\begin{tabular}{|c|c|c|c|}
\hline 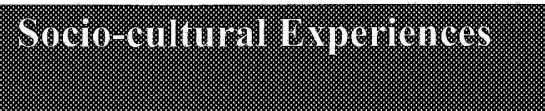 & Unversity I Elucation & Hirancis) & $\begin{array}{l}\text { I.ans and } \\
\text { Rrghts }\end{array}$ \\
\hline $\begin{array}{l}\text { Ability to navigate culture shock and } \\
\text { isolation } \\
\text { Ability to engage with others in } \\
\text { Canada through social interaction, } \\
\text { making friends, dating } \\
\text { Ability to resolve gender related } \\
\text { issues/interactions } \\
\text { Ability to maintain transnational ties } \\
\text { with family and friends } \\
\text { Ability to engage with food system in } \\
\text { Canada } \\
\text { Ability to engage with day-to-day } \\
\text { functioning in Canadian life } \\
\text { Ability to navigate in urban and rural } \\
\text { landscapes (ie. Transportation) }\end{array}$ & $\begin{array}{l}\text { Ability to navigate in } \\
\text { Canadian university (ie. } \\
\text { Study habits, academic } \\
\text { integrity, teaching styles, } \\
\text { managing course/work load, } \\
\text { etc.) } \\
\text { Ability to connect academic } \\
\text { choices with career paths }\end{array}$ & $\begin{array}{l}\text { Ability to manage and } \\
\text { understand Canadian } \\
\text { finance systems and } \\
\text { personal finances } \\
\text { Ability to engage with } \\
\text { Canadian employment } \\
\text { process }\end{array}$ & $\begin{array}{l}\text { Ability to deal } \\
\text { with racism, } \\
\text { discrimination } \\
\text { and appropriate } \\
\text { gender } \\
\text { interaction } \\
\text { Understanding } \\
\text { personal rights } \\
\text { and rights of } \\
\text { others } \\
\text { Ability to access } \\
\text { public safety } \\
\text { services }\end{array}$ \\
\hline
\end{tabular}

succeed within the cultural context. Although cultural capital is generally acquired unconsciously from within a familial unit, those who do not have access to the avenues of inculcation must deliberately seek opportunities to acquire cultural capital (Bourdieu, 1973, 1986). It is through an investment of time and effort to acquire the cultural competencies that one will likely increase their cultural capital, encouraging individual autonomy and a more complete contribution to the receiving society and in return, the society giving back to the individual (Bourdieu, 1973, 1986).

The concept of social capital addresses the notion of having social networks or comnections that enable access to an aggregate of resources or opportunities that increase the functionality of an individual in a particular social group or society (Bourdieu, 1983, Kunz, 2005; Portes, 1998). Membership to a particular social group often relies on the degree to 
which an individual has knowledge and use of the cultural competencies found in cultural capital (Bourdieu, 1986; Portes, 1998). Despite the complex, multifaceted application, and elusiveness of the concept of social capital (Portes, 1998), in the context of this research study it simply alludes to the idea that when someone leaves a community, they tend to loose their established social networks and bonds. In entering into a new community, new social networks must be created to enable access to opportunities within the new socio-cultural milieu. By creating new social networks within a new social environment, an individual is accumulating avenues, which they can make use of to fully immerse themselves in the new culture and garner more cultural capital. Essentially, the degree to which newcomers can encapsulate cultural capital and diversify their social networks will make them more likely to successfully resettle and integrate in the Canadian context (Kunz, 2005).

Portes (1998) notes that Bourdieu's theories of cultural and social capital function to demonstrate the role these factors play in economic gains in the context of social class. I am not diverging too far from this notion, as economic participation is one element of resettlement for newcomers, but I am expanding the concept to include the construction of cultural and social engagement for the student refugees. Accessing cultural and social capital enables SRP participants to gain an understanding of how to navigate within Canada, socially, culturally, academically, politically, and economically. When applying cultural and social capital to the analysis of the role of P-DCO for refugees destined to Canada, the orientation clearly takes the place of socialization. Socialization is a concept Bourdieu uses at length, which encourages the development of tangible resources that can be used to navigate the new culture. By imparting relevant information on cultural competencies, through cultural training, and making connections with those already in Canada, the student refugees can more thoroughly grasp the codes and tools and employ them in the social networks they are exposed to. 
As the literature demonstrates, it is evident that the notions of social and cultural capital are important in the resettlement process of refugees. Having access to cultural knowledge prior to departure, and access to social supports during the resettlement period can enable more successful resettlement.

\section{Methods and Data Analvsis}

This study is exploratory in nature, using qualitative research methods. After reviewing the relevant literature, it is apparent that there is a need for academic research to account for the paucity of information on the role of Pre-Departure Cultural Orientations ( $P$ DCO). The voices of those who have received P-DCO are imperative in the discussion of the relevancy of pre-departure preparation for refugees. Considering this, I engage with the participants of the Student Refugee Program (SRP) to gather their experiences and stories of their pre-migration preparation as my sole source of data.

I believe that within the qualitative research approach, interpretive social science (ISS) best reflects my values and assumptions as a researcher. The ISS method or phenomenological study, allows me to examine the role of the P-DCO from the vantage point of the SRP participants who actually experienced it (Locke, Silverman, and Wyrick Spirduso, 2004). I truly value the process of understanding the social realities through the perspectives of the participants, while developing a rapport with the participants. Furthermore, the ISS approach encourages the assessment of individuals' values as diverse, where no one is wrong, only different (Neuman, 2006). I believe that not imposing value judgments on participants in the research study opens the door for more open and inclusive experiences, for both the researcher and the participants. This methodological approach uses data gathering and analysis techniques that shape the kind of research outcome that I feel is socially useful. 


\section{Sources of Data}

This study contains two sources of data, which were collected during the months of June and July 2009. The first source of data was a key informant interview with the SRP Senior Program Officer, Asni Mekonnen. The second data source was collected through indepth interviews with SRP participants now living in Canada that would have received a PDCO in some capacity prior to their departure to Canada. These two data sources allowed me to focus the research and gather a more complete perspective regarding my research questions. Both angles, from participants and administrator, combine to illustrate the imperative role of pre-departure preparation, especially in the context of refugees.

\subsection{Data source \# 1}

I conducted one key informant interview with the SRP Senior Program Officer, Asni Mekonnen. Ansi is responsible for the selection and placement component of the program in regards to the sponsored students. She works closely with the overseas partners, as well as the universities and local committees, which sponsor the SRP participants. Asni has been in this position for 5 years. The interview with Asni took 45 minutes and was conducted at the World University Services of Canada (WUSC) head office in Ottawa, Ontario, in one of their conference rooms. Prior to commencing the interview, Asni agreed that I could record the interview, which I transcribed the following day.

\subsection{Data source \#2}

Through in-depth, semi-structured interviews with SRP participants, I was able to directly explore the research questions by drawing on the experiences of SRP participants from their memories. This primary data highlights the issues that are essential for SRP participants during their journey and resettlement to Canada and to university. 
I chose the interviewees from responses received through a snowball sampling method. I posted an informative recruitment flyer (See Appendix A) to the Canadian Council for Refuges (CCR) email list-serve. Then, through support from the WUSC, they sent out the recruitment flyer to former and present SRP participants who migrated to Canada between 1998 and 2008. From those networks I was able to gather the sample size and composition I required. This sampling method served to increase trust from the participants, as the call for participants came through channels with which they were likely familiar. The interviewees contacted me directly to express interest and find out more about the research and the interview process. Through continued communication with those who contacted me, I tried to make clear my position as a researcher, a WUSC local committee member, and also my genuine interest in their individual stories.

I was able to conduct six in-person interviews. Through email correspondence prior to the interview, I presented the participants with an idea of what the research was going to entail. At the beginning of the interviews I had the interviewees fill out an intake form that had demographic questions (See Appendix B). The collection of this data enabled me to situate their individual experiences in relation to other interviewees. The interview questions were developed to draw on specific experiences pertaining solely to the P-DCO. The guiding interview questions (See Appendix C) were open-ended, as this encouraged the sharing of significant input pertaining to the experiences of the SRP participants related to the various forms of pre-departure preparation they received.

Each interview took approximately 1 hour and 30 minutes. All six of the interviews were in-person, conducted in locations generally put forth by the interviewees where they felt comfortable and it was convenient for them and their schedule. Four of the interviews were conducted in Toronto, Ontario. I traveled to Ottawa, Ontario for two of the interviews, and 
similarly met those participants at locations that were convenient for them. With permission from the interviewees I recorded and transcribe the interviews verbatim ${ }^{3}$. I refrained from taking notes during the interviews unless necessary for a follow-up question, as I thought this would distract the interviewee and potentially have them perceive me as less engaged and uninterested in their comments and experiences.

All participation was voluntary, unpaid and anonymous. Remaining anonymous was quite important for most of the participants as this ensured there is no opportunity for their truthful and sensitive responses to be identified. For this reason, the quotes included in the finding are not tied to the real names of the participants.

\subsection{Sample}

The sample in this study consists of six SRP participants who arrived in Canada through the SRP program between 1998 and 2008. Five of the participants in this study are male and one is female. The participants' countries of origin varied and include, Ghana, Liberia, the Democratic Republic of Congo, Rwanda and Sudan. Similarly, the mother tongue of the participants was diverse and included, Dinka, English, Kimyarwanda, and French. The academic institutions that the participants were sponsored by, and attended, range from coast to coast.

Notably, the sample size is relatively small in accordance with the number of SRP participants that have come to Canada during the time frame mentioned. Due to the limitations of the study, and in consideration of the time and resources I had, I was unable to interview all interested participants, who could have been valuable contributors to the findings.

3 To transcribe the interviews I used a voice to text software called Dragon Naturally Speaking that significantly decreased the time that I had originally been advised the transcription process would take. 


\section{Data Analysis}

I implemented the analysis method of coding the 6 SRP participant interview transcriptions. During the first read through of the transcriptions, I extracted 6 prevalent themes that ran throughout the interviews (Locke, Liverman, \& Wyrick Spirduso, 2004). Those themes were: General comments about the orientation, orientation facilitation, sociocultural experiences, university life, financial experiences, and laws and rights. I used those 6 main themes in re-reading the transcriptions, and coded comments or experiences that fit into the respective categories. I then broke the transcriptions into these 6 themes and re-examined the text in the categories to identify sub-themes. These coded themes and sub-themes are used as the organizational categories for my findings. I used the key informant interview to establish the discussion on the nature of the P-DCO.

\section{Limitations}

This being a qualitative study, I was the sole tool in collecting, and analyzing the data. For that reason, I must address the presence of my subjective biases, as they have undoubtedly contributed to my research design (Courtney, 2007; Merriam, 2002). My subjectivity, no matter how hard I try to put it aside in analysis, is the lens through which I interpret the data. I attempted to remain impartial, bringing forth my subjectivities and biases throughout the research process and, insofar as I could, I monitored them and how they contributed to the research as a whole (Courtney, 2007). To account for my research position I employed peerreviewed interview and analysis strategies and have used direct quotations in the findings.

Another limitation to the data and research findings is the sample size, ethnic background and gender make-up of the group. The small sample size is attributed to the time constraints and resources I had available to me in conducting this research. Although it is a small size, the participants that did contribute reflected on their realities and were open and 
expressive during our discussion of their experiences. From this sample, it is important to note that all of the interviewees' countries of origin were in Africa. While some SRP participants have migrated from Asian nations through refugee camps in Thailand, I am not aware of any responses from SRP participants who migrated from Thailand, therefore their voices are not present in the findings. In regards to the gender make-up, many of the refugees who come to Canada through the SRP are male. Education in many African nations is primarily focused on males in the family, while females commonly take on more responsibility within the family at home. Due to this, there is likely a significant gender-bias in the results, despite the one interview I did with a female SRP participant.

Addressing the individual participants' demographic and experiential profiles would be valuable in this study. As well, establishing individual participants year of arrival and the length of time they have lived in Canada could provide a more comprehensive presentation of their individual perspectives of the P-DCO. These contributing factors are important in determining the effectiveness of the P-DCO; however, due to the small number of SRP participants that come to Canada each year, providing individual profiles of the interviewees would likely make it easy to identify the participants. Therefore I have limited the specific information attached to each interviewee.

Finally, in the context of the key informant interview, it would have been beneficial to include the perspective of an employee from the IOM. IOM employees are the ones who administer the COA to the SPR participants prior to departure. Without this point of view, the methodological concept of triangulation is limited to just two points of reference, the SRP participants, and the WUSC, SRP staff. 


\section{Findings}

The Student Refugee Program (SRP) participants spoke generously about their experiences and memories of their individual Pre-Departure Cultural Orientations (P-DCO) process, and highlighted some consistent themes that they felt were advantageous, or lacking in the orientation. Drawing on material from the International Organization for Migration (IOM) and the World University Services of Canada (WUSC), I put together a table that illustrates the current components of the IOM and WUSC orientations, which correspond with the categories of what constitutes cultural capital as outlined in the theoretical framework (See table 2). Because each interviewee came to Canada in a different year, their experiences include varied combinations of differing P-DCO facilitation methods. All of the participants had access to the Pre-Departure Guide for WUSC Sponsored Students, but the handbook has evolved over the years, and due to the 10-year time gap between some interviewees' arrival dates, participants received different editions. Some participants received longer orientations from the IOM, spanning several days, while others received a one or two day orientation from the IOM. Three of the participants also had orientation workshops with Canadians who came to the refugee camp. There is little consistency in regards to what each participant received prior to departure, however all of the SRP participants in this study did engage with some degree of pre-departure preparation provided by WUSC or the IOM.

The findings are presented in the thematic groups that emerged from the coding process. They are: General comments about the orientation, orientation facilitation, sociocultural experiences, university life, financial experiences, and laws and rights, and the key informant interview informs the discussion on establishing the nature of the P-DCO. These themes work together to address the guiding research questions of this research initiative. 


\begin{tabular}{|c|c|c|c|c|}
\hline & 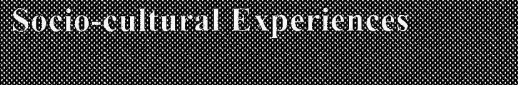 & 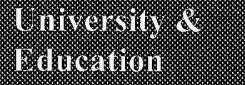 & 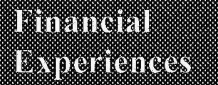 & 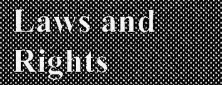 \\
\hline $\begin{array}{l}\text { Intemational } \\
\text { Organization } \\
\text { for } \\
\text { Migration, } \\
\text { Cultural } \\
\text { Orientation } \\
\text { Abroad }\end{array}$ & $\begin{array}{l}\text { Facts about Canada (geography, } \\
\text { political system/government structure, } \\
\text { languages) } \\
\text { Transit } \\
\text { Culture shock } \\
\text { Families in Canada (relationships, } \\
\text { nutrition, hygiene, diet) } \\
\text { What is social welfare? } \\
\text { Communications } \\
\text { Climate in Canada } \\
\text { Finding a place to live } \\
\text { Adjusting to Canada, settlement } \\
\text { services, etc. }\end{array}$ & $\begin{array}{l}\text { Education (levels, } \\
\text { teaching styles) }\end{array}$ & $\begin{array}{l}\text { Employment in } \\
\text { Canada } \\
\text { Cost of living }\end{array}$ & $\begin{array}{l}\text { Living in a } \\
\text { Multicultural } \\
\text { society (respect, } \\
\text { diversity, } \\
\text { equity) } \\
\text { Rights and } \\
\text { responsibilities }\end{array}$ \\
\hline $\begin{array}{l}\text { Pre- } \\
\text { Departure } \\
\text { Guide for } \\
\text { WUSC } \\
\text { Sponsored } \\
\text { Students }\end{array}$ & $\begin{array}{l}\text { Overview of the SRP program } \\
\text { including goals, timelines and SRP } \\
\text { participants responsibilities } \\
\text { Traveling to Canada (what to pack; at } \\
\text { the airport; first few weeks; } \\
\text { accommodation; food; health care; } \\
\text { orientation at school } \\
\text { Canadian characteristics and customs } \\
\text { (understanding Canadians; climate; } \\
\text { weather/seasons; history) } \\
\text { Adaptation and culture shock (stages of } \\
\text { culture shock; coping) } \\
\text { Daily Matters (communication; food; } \\
\text { entertainment; common names; } \\
\text { shopping) } \\
\text { Health care } \\
\text { After the one-year sponsorship }\end{array}$ & $\begin{array}{l}\text { Academic issues } \\
\text { (Canadian edc. } \\
\text { system; courses; } \\
\text { services) }\end{array}$ & $\begin{array}{l}\text { Money matters } \\
\text { (budgeting; } \\
\text { tuition; } \\
\text { clothing; } \\
\text { essentials; } \\
\text { school supplies; } \\
\text { allowance; } \\
\text { loans; } \\
\text { remittances; } \\
\text { credit cards; } \\
\text { banking) }\end{array}$ & 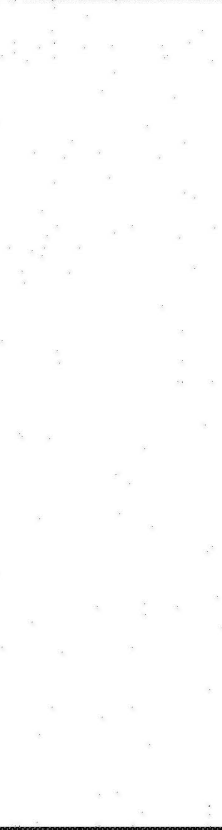 \\
\hline
\end{tabular}

The main themes are also representative of what constitutes the necessary cultural capital, and speak to the essential cultural competencies required to facilitate successful SRP resettlement. 


\section{The Nature of the Pre-Departure Cultural Orientation}

The key informant interview provided a more complete understanding of the nature and function of P-DCO in the SRP participants' development of cultural capital. Through discussion with Asni, the key informant from the SRP, I was able to flush out a more complete understanding of nature of the P-DCO that the SRP participants receive. Asni was able to speak to the function of the pre-departure handbook that has been developed to provide SRP participants with a general overview of what they should expect during their resettlement in Canada. As well, she herself does try to meet with the groups of students prior to departure some time in June every year to speak to them and ease any concerns that they may be facing.

Asni could not comment on the effectiveness of the IOM orientation, because the IOM COA is provided to most refugees that migrate to Canada, and WUSC has no say as to what is included in the IOM's orientations. However, Ansi did indicate that the IOM orientation does not address resettlement issues in the context of post-secondary education. The IOM orientations give a basic overview of Canada, and attempt to tailor the sessions to specific groups of refugees.

What makes it very difficult for the IOM, I mean I haven't sat in their orientation, but sometimes there are urban refugees, and sometimes there are nural refugees. And sometimes they are literate refugees and sometimes there are illiterate refugees, so the urban refugees for example, they may know how to use all of the kitchen facilities where the rural refugees may not have any idea. So sometimes depending on the group that they will have they might have a two-day session, a five-day session, or a three-day session. So it depends on who is part of the group. So for us mostly we expect them to get the general information [...] (Asni)

For that reason, WUSC tries, where possible, to supplement the pre-departure information needed for developing SRP participants expectations of university. This is achieved through the WUSC handbook, as well as orientations and information sessions led by WUSC representatives, Canadians, or Canadian students. Asni suggested that pre-departure 
preparation is in place essentially to prepare the SRP participants for their transition to life in

Canada and at their universities.

Well the objective for the IOM and WUSC in terms of the pre-departure is, to give accurate information about Canada, help immigrants develop realistic expectations, because sometimes when you're overseas and the grass is greener, and then when they come it's different. Also, awareness and skills necessary for successful, in terms of a successful completion of their studies, and in terms of the educational environment, like simply making sure that the professors are accessible in Canada. [...] the objective is to explain to them, to curb their expectations and to begin their life on realistic footing. (Asni)

By providing insight to the SRP participants prior to departure about what to expect through various methods of orientation, WUSC believes it minimizes the mistakes and challenges the students may encounter during their resettlement.

The WUSC handbook, and other pre-departure information administered by WUSC, is based on a framework that engages with the important elements of resettlement, while linking resettlement with anticipated experiences in the students' education. Although the goal of PDCO is to create realistic expectations and decrease stresses associated with resettlement, due to the limitations in the length of time it is administered, the orientations cannot ensure the participants are adequately prepared. Asni mentioned that each individual student would have different personal resettlement experiences, depending on the totality of their life experiences.

\section{The SRP Participants Perspective of Their Orientation in General}

When asked about their knowledge of Canada, all of the participants felt they had some information about Canada prior to receiving the P-DCO. Some had been exposed to the geography and the physical environment through their studies in high school or university. As well, some of the participants had seen images on television. Over all, most participants had images and ideas of Canadians, and Canada as a country, before leaming anything in their orientations. From what the participants said, there was much need and interest to learn about 
the culture, social behaviours, and what life, and more specifically student life would be like in Canada from their orientations.

The consensus from the participants was that they found some elements, if not most of the orientation, helpful in the context of when they arrived in Canada. Many of the participants said that they felt the orientation informed them of things they should expect, providing them with general and appropriate cultural competencies to apply upon resettlement. Participants felt the P-DCO eased some of their concerns pertaining to their travel and initial resettlement, including what life would be like in Canada and at their university. Those who received longer orientations, or orientations with Canadians, felt they were able to engage more deeply in some of the issues they would face. Some interviewees drew on specific information, or facilitation methods, that they believed were useful or lacking. Others spoke more generally about how the orientation process could have been improved to further develop cultural capital, and be more applicable to what they experienced when they arrived in Canada and at their university.

Actually I got enough information about the culture in Canada, about politics, um, information about work related employment, school, um what else. The rights of Canadians - how to become a Canadian. (Interviewee \# 4)

[...] the book was really precise about things. [...] So the things that I didn't, that I was not used to doing, like shopping, like how you handle money, how you talk to people, personal space, and sexual harassment, and stuff. So, there were really specifics that I really benefitted from, from reading the book. (Interviewee \# 3 )

Well the strengths certainly is that we had good information about the place we are coming to. [...] it was just really great to have those information reduce the stress and then when we got to Canada, the same thing. (Interviewee \# 6)

Whether it was through reading the WUSC handbook or engagement with a facilitated orientation, the participants valued whatever information they received. However, many of the interviewees stated that, after their orientations, they had unanswered questions that were important to their individual journeys. 


\section{Orientation Facillation}

The P-DCO that the participants received was delivered using various methods and tools. The interviewees expressed differing experiences as each of them responded differently to the tools and methods used to facilitate their orientations. Participants mentioned the length of the orientations, films and visual aids, books, interaction with their facilitators, and appropriate examples as factors contributing to the effective delivery of information.

\subsection{Orientation Length}

Three participants emphasized the length of time of the orientation as substantially contributing to their lack of feeling prepared. The participants felt that, due to the short time period, they were not able to have all of their questions addressed. It seems that the longer the orientations were for participants, the more prepared they felt after they arrived in Canada.

One participant stated:

Yeah the information that was given was a few hours. I want to emphasize that those few hours, at least I took it into my system and it was part of me but the time was not enough, just only two days, on each day I remember we used to have only for four hours each day. The total cultural orientation took about eight hours for two days, and I remember two hours of the eight hours we used for watching movies. So that means we had six hours of cultural orientation and I think that is the reason as to why the amount of substance given during the orientation was not enough. [...] I was not prepared, I was not prepared because the stuff that I got in the orientation was not sufficient enough to make me say oh I have known this [...] (Interviewee \# 2)

While another participant echoed those feelings:

The negative is that it wasn't enough, because we had so much more questions to ask afterwards, it was information overload, I mean we left over there probably five or six in the evening and we started at nine or 10 in the morning, we had one hour lunch break, it was a lot. (Interviewee \# 6)

Despite feelings that the length of the orientation was not sufficient to address their needs and questions, four participants noted that too much information was provided at one time. These participants believed that spreading the orientation out over a longer time period would have 
enabled them to absorb the information provided, and given them opportunities to reflect and clear up any questions.

Similarly, one participant suggested that the time allotted to different topics covered in the orientation could have been better prioritized. Two interviewees identified a need for a clear distinction between information that was highly important to their resettlement, and information that they felt was less important after arrival. One participant suggested that the IOM classify the information they provide to ensure priority is placed on topics and issues that are prevalent in the resettlement process:

[...] but again is in the context of that, you can speak about whatever you want in that context unless you don't put priority on them nobody is going to separate which one is good and which one is bad. (Interviewee \# 5)

Another participant alluded to the factor of SRP participants being so excited during the time they receive the orientation that it can be challenging for them to absorb the information they will require during resettlement.

Because when we arrived here we, like me I think after four days I started school and you start becoming busy and then you don't realize what kind of information you have gotten immediately. Just as time goes by, that is when you start to discover, like I wish I knew this. (Interviewee \#1)

Information can be difficult to retain during the pre-departure period, and the interviewees could have benefited from a more structured and prioritized grouping of information to grasp the cultural competencies necessary.

Participants also discussed the relevance of the orientations they received with regards to their expectations of university life. While WUSC provided the participants with university specific information, none of them felt that the IOM orientation engaged with university life in Canada.

I didn't really know anything about the similarities between the orientation that I got and the university life here from the IOM. (Interviewee \# 2) 
SRP participants are a unique group of refugees that receive the general COA with other refugees resettling to Canada. Because the IOM provides orientation to different groups of refugees, they do not focus on connecting resettlement experiences with university life. Such connections would be valuable to the SRP participants in their P-DCO.

\subsection{Films and Visual Aids}

Films were used in the IOM orientations to provide visual images and prepare the participants for what they may see upon arrival in Canada. Most participants expressed that the film was useful in their orientation, although it seemed to them to be outdated. Three participants suggested that portraying a specific city and time period in the film created unrealistic expectations for the participants, if the city they were destined for was not the same as those in the film.

I think the movie was more effective, even though it was an old movie. The date of the movie, I will say 1980s, because you can even see the buses and they were very different from what you were seeing. The movies were, you could see they were old. And when you get here you think they are even older than you expected they were in the first place. But things change, they should've told us which city because you can see maybe like this bus, in Toronto buses will be renewed every time, and Montréal maybe also every time, but maybe in another city they will have all of those old buses, maybe it is also depending on, because I compared it on the buses they were showing us. (Interviewee \# 5)

Although this participant found the film to be useful despite the city and time context, others had more difficulty relating.

[...] we were shown a movie of Canada [but] I don't even remember it. Seriously, I think I have a very good memory and if the film was something that, because visuals do stick with people, if the film was meaningful, [...] you can remember something if it has some kind of impact on you. But the film didn't really. (Interviewee \# 6)

While the film was not helpful, or even memorable, for this participant, another visual aid was said to be useful. The participant felt that the discussion and image of the culture shock curve was applicable to their circumstances during resettlement. 


\subsection{Orientation Books}

The WUSC pre-departure handbook and other informational books provided to the SRP participants were seen as valuable by the interviewees. All participants appreciated being able to supplement information received in their IOM orientation with information from their books. However many participants expressed the desire to ask questions related to the books content, which there was insufficient time for in any of the orientation sessions.

\subsection{Orientation Facilitators}

The five participants that took part in the IOM orientation felt they were able to relate, in some way to the facilitator. All of these participants said that at least one of the people who facilitated their orientation with the IOM had lived in Canada at some point during their lives. The participants felt the facilitators provided them with information that had personal experience tied to it. Some participants believed that those who facilitated their orientation had been refugees at some point, who were now working with the IOM.

Areas of contention pertaining to the facilitators, that participants mentioned, were their age and use of language. One participant felt that the facilitator was not of a relevant age to be leading an orientation for young, student refugees. The interviewee did not feel they were able to connect with the information the facilitator was sharing around the context of current youth culture in Canada. Similarly, the interviewee suggested that the English dialect of the facilitator was quite formal and not connected to current Canadian youth slang. The interviewee believed that these two areas were important in their preparation and engagement with the orientation.

Participants, who received an orientation facilitated by Canadian students, or others outside the IOM, found it extremely useful and applicable to their experiences at university when they arrived in Canada. The participants valued the opportunity to interact and speak 
with Canadians that were of a relevant age. Through contact with Canadians, the participants were able to grasp social contexts of life in Canada and hear Canadian English and accents. As well, they felt they were given more opportunities to ask questions in this format of interaction, because these orientation sessions were less formal, allowing more opportunities to engage with the facilitators. One interviewee described how their experience with the Canadian students, who visited the refugee camp, impacted their resettlement:

[...] when I came to Canada I knew I was not $100 \%$ familiar with everything, but at least I was $60 \%$. Because my transition to the Canadian system was not very hard, one because I knew two Canadians already before [...] (Interviewee \# 2)

The participant stated that if they had not received the separate orientation with the Canadian students, they would have likely felt only $40 \%$ familiar. It is evident that participants' valued interaction with Canadians prior to departure, as the development of social and cultural capital was effectively facilitated, having positive implications on their resettlement into Canada and at their universities.

Comparable to having face-to-face contact with Canadians, all of the SRP participants receive some form of communication with their sponsoring local committees prior to departure. Participants indicated that they were sent a package with information about the university and the destination city or town, often including photographs of people they could expect to see upon arrival. This contact, prior to departure, allowed the students to develop ideas of where they were going, and whom they would be depending on for support after arrival. Those who did not receive orientations with Canadians found this contact extremely valuable, contributing to their social networks during resettlement and integration.

\subsection{Appropriate Examples}

Independent of the facilitator, or the facilitation method, is the necessity of providing appropriate examples to SRP participants. As one participant stated: 
Like in the orientation they said Canadians are mostly more social than Europeans, for example they would give us an idea, but we don't even know about Europeans [...] They could compare it to Kenyans in the city they could compare the village and the city. [...] So a more relevant comparison would have been helpful. (Interviewee \# 5)

Since the orientation is meant to construct ideas and expectations, it is important to use appropriate examples that create tangible connections between what participants know and what they will experience during their transition to life in Canada. Similarly, one participant mentioned that poor examples were used when discussing financial realities.

Make a comparison. So that means when you hear 5000 , it's not 5000 in Africa, it's 5000 like 3000 in Africa. Because the money you have here is not as much as if you had it back home. [...] Like in the refugee camp we already found that the same money in the refugee camp is more than the same money in the town, so they could just make the link that, you see here the way you are using 3000 , think about that 3000 in Nairobi, is it enough? (Interviewee \# 5)

While it is complicated to completely convey ideas and concepts of what to expect in circumstances that have never been experienced, the participants were able to identify areas where they believe more relevant examples would be effective. By using appropriate examples, the orientation could contribute to the creation of real expectations of life in Canada.

\section{Socio-cultural Experiences}

In the context of socio-cultural experiences related to their orientation and resettlement, the participants in this study focused quite heavily on cultural competencies related to feelings of culture shock and isolation. Many discussed issues surrounding the challenges of social interaction, making friends, dating, female specific issues, and maintaining connections with family and friends. Participants also spoke about interactions with their environment, such as weather, food, living in cities and towns, and commonplace items used in their daily routines. 


\subsection{Culture Shock and Isolation}

The two interviewees that spoke about culture shock had been exposed to the concept during their P-DCO from a WUSC representative and Canadian students. These interviewees felt that understanding the culture shock curve was quite useful during their resettlement and adjustment period. They were able to identify what stages of culture shock they were experiencing, which gave them a reference point to connect their feelings with their experiences.

The topic of isolation was something most of the participants were exposed to during their orientations. Most participants said that they were not well prepared for their feelings of isolation during resettlement, as they were far greater than anticipated. One participant described how the concept of isolation was explained to him:

[...] one of the things that they said was that it is normal to anybody who gets to a new place to feel isolated, to feel like he's being neglected. It is not that he or she is being isolated but it is because he has not yet adapted to the situation or he has not known anybody before to socialize with just as in a normal situation. (Interviewee \# 2)

The participants were aware of the need to make connections with people at their universities, to address their isolation. However, the participants felt the challenges of overcoming cultural differences and lack of competencies impeded their ability to meet people.

They should really tell us because during the period of culture shock where you are so depressed and everything, that is when you are really looking for friendship and people are just not used to your kind of friendship. You can't just knock on somebody's door and say, 'oh I'm feeling low, I just want to come and have a chat'. People are busy in this culture - they need to mention that. This culture is based on time and everybody is busy. So you can't just lays and sit under the mango tree or the coconut tree and chat, you got to plan, you have to make the time, so they should really stress on that. (Interviewee \#6)

The participants also realized that the cultural differences created a feeling of not fitting in, which caused them to isolate themselves from their peers. The participants were not able to rely on their normal methods of dealing with loneliness and isolation, feeling that their methods did not fit into the Canadian context. 
Like coming from Kenya, it's a country where you are not even used to seeing many white people. You see, like you arrive to school and then to make friends it's difficult [...] So you find because you are new there and you are just by yourself, you isolate yourself, and yeah sometimes it's hard. [...] yeah like the way in Africa it's easy when you are alone, you just go to someone's house and chilled there and talk. But in Canada everyone is busy, everyone is busy you cannot just show up like that [...] (Interviewee \# 1)

Isolation is a feeling that one cannot necessarily be prepared for. However, the orientations received by SRP participants could engage more with the concept of isolation and culture shock to convey the cultural competencies necessary to navigate culture shock and isolation. Understanding their isolation, and being prepared with effective methods of dealing with loneliness will help the SRP participants to focus more on their education.

\subsection{Social Interaction}

Many of the participants discussed their experiences with social and relational encounters. Few participants stated their orientations addressed some components of interacting with others in Canadian society, but they still identified aspects of interaction that they felt would have been relevant during their resettlement. Many of the participants' comments revolved around challenges of adapting to the soft skills of Canadian culture. Although the participants are loosely provided with the cultural competencies of social behaviours in Canada, it can still be challenging in practice. One participant discussed the difference in personal space between cultures:

[...] the most striking was personal space. In my culture we, our personal space is almost zero. We bundle all together, and we don't care. Here, personal space goes from half a meter to over a meter. If you step in that space you will start seeing the other party reacting, or acting in a different way; meaning that you have stepped in their personal space. So, that information to me was very important, because otherwise people would start judging me or look at me differently and think I am funny or crazy or something because I was acting outside of the norm that is accepted [...] (Interviewee \# 3)

Similarly, the social practice of making eye contact presented a difference in interaction that one participant was not accustomed to. The participant explained that eye contact between men and women in their culture was something that was done only when approaching a person 
to marry them. Where as in Canada, they encountered eye contact as an important component to daily social interaction.

In [Canadian] society if you [don't make eye contact], they will think that maybe you are uninterested or you are avoiding the other person, so you have to look at someone in the eye. In my culture that's not allowed. (Interviewee \# 3)

Apart from the nuances of general interaction between Canadians, most of the participants discussed interacting with the opposite gender, and what was considered appropriate. The interviewees generally indicated that they had been made aware, through the orientation, about the difference in social interaction between men and women in Canada. Despite the information that was provided, two participants described how they were still quite shocked when they actually experienced it.

[...] in relation to men and women. In Africa we live in our parents house. We don't go anywhere with nobody. We don't live around girls, things like that. But, in residence, oh my god my next door neighbour was a woman. I go to the kitchen, $90 \%$ of the people who are in there are women. Oh my god, that was terrible, but knowing that relationally here in Canada it's ok to live around women. It's ok to be around them, except that, you know, you don't step in their personal space, made me more comfortable to be in that residence. (Interviewee \# 3)

Like those things, it didn't really come up in the orientation, which was a problem because, just relating to the opposite sex in Canada was a problem, you know? [...] just the issues about rape or not feeling comfortable when somebody touches you in a certain way, and that maybe the Canadian context is more liberal, it's more open, people touch you. In our culture you can't even do that. (Interviewee \# 6, Female participant)

What many of the participants perceived to be normal ways of interacting with others did not

fit into their new Canadian context. Some participants believed that the orientation could have better prepared them, by providing the cultural competency applicable to gender interaction with Canadians.

\subsection{Dating}

Beyond simple interaction between genders, the concept of dating was a significant issue for some of the participants. As one participant stated, "[...] most of the people in 
WUSC are young and dating is something that they can do any time." (Interviewee \#1).

Dating, though, is an elusive concept, which can be interpreted differently between cultures.

Understanding the complexity of interacting with someone of the opposite gender, and how certain actions can be perceived to have romantic overtones in the Canadian context is important.

What is dating? Is it sleeping with [someone]? Is it taking them for a movie? Is it taking them for a drink? Is it taking them for coffee? Is it just communicating with them through email or something? It's a broad topic that I don't know if I know now. So, those kind of things that you have to learn over time. Of course that [orientation] book cannot cover everything, but those are a few things that I wish I had known. (Interviewee \#3)

The participants found that, due to its complexity, dating was a difficult concept to address in their P-DCO, however they felt it was relevant to their resettlement experiences.

\subsection{Making Friends}

Similar to the issue of understanding dating practices, most participants spoke about the challenges they faced when it came to making friends at university. The SRP participants are in a unique situation as refugees, because their sponsoring local committees provide avenues to make friends and learn the customs of Canadian youth culture. The participants indicated that, through their orientation, they were made aware of the difficulties they could expect when it came to making friends at university.

I was prepared for the fact that university students come from different parts of the world, and especially first-year everybody does not know anybody. Everybody do not know anybody, so it is your responsibility to know somebody who does not know somebody. (Interviewee \# 2)

Making new friends is not only dependent on being aware of the difficulties, but also on the personality of each individual. As new students at a university, in a different culture and social environment, participants spoke about the difficulty of expanding their social networks to include people other than those from the same ethno-racial or linguistic background. 
Let's say because for example, if you are a refugee and I'm a refugee and we are coming from somewhere and we are on campus or we are in the same town, if we are just to interact, just me and you only, there is not much we are going to learn. But when we get integrated into other groups, but mostly refugees, like whenever they get here, they think. because I know this person from back home and I know this person, only those people have to be my friends. They are trying to be close to people that you know, and later on you realize you have missed so many things. When people are getting here, try to make friends. (Interviewee \# 4)

But here it's not the same, people who you came with from the camp, end up being the majority of people you know in Canada at a certain time, even for a while. Sometimes even for some people who are not very open-minded or outgoing, they end up being with those they've known since the refugee camp. (Interviewee \# 5)

One participant described the difficulty making friends in Canada, suggesting the concept of friendship is different in Canada compared to what they knew back home.

[...] friendship in Canada means a whole different thing. In most of Africa, at least I have traveled to 16 countries there, I can make such generalizations, if you meet somebody for the first time they are your friends, you can smile with them next day, you can have food with them, but not in Canadian context. (Interviewee \#6)

Although participants found meeting friends and having meaningful relationships with people in Canada to be challenging, some participants discussed strategies that they felt were useful in breaking down feelings of isolation and integrating into the larger social context. All of the participants spoke about how they were encouraged, through their P-DCO, to participate in the WUSC local committee. However, some felt that other social clubs and activities on campus were not adequately discussed in their orientation.

Like things are not really linked, like I wouldn't say somebody told you, like there are clubs in school, no, clubs, actually there are so many clubs in school, [...] no that aspect was not there. Like you can find, even for me to know clubs, it was after the first year that is when I started knowing clubs, after one year. (Interviewee \# 5)

Four participants discussed the importance of developing social networks during their resettlement, especially within their universities. By having information about what social clubs are at their destination university, SRP participants can anticipate clubs they may join to meet people with similar interests in Canada. Despite the fact that the orientation could not 
completely prepare participants for every social interaction they encountered, providing them with some basic understanding of social networking at university could have reduced their stress.

\subsection{Drinking and Drug Culture at Canadian Universities}

It is important that SRP participants are informed about drug and alcohol use at Canadian universities. Many interviewees indicated coming from environments where drugs and alcohol were not present, or at least were not used in the same context as at Canadian universities. Two interviewees had differing feelings about how prepared they were by their P-DCO to navigate situations with drugs and alcohol. Both interviewees, however, addressed the notions of peer pressure and fitting in, and how drugs and alcohol play a role in making friends at university.

Again in terms of university life, [...] the whole culture about drinking, you know most of us come from a culture where we don't even drink or smoke so they need to [know]. [...] But again, everybody drinks and because, because you are not used to the culture, [...] you find yourself in this situation where, you are not confident enough to say no I can't drink or no I don't want this. [...] It's just that you just want to fit in. But if they can reinforce that in the culture, no, in Canada you don't have to fit in, you can be bold, you can be strong, and refuse what other people offer you. You can outright say no, and nobody will feel negative about you, it's okay, you know? (Interviewee \# 6)

Like okay I know this person, but this person is on drugs or something like that, it's okay I can still talk to the person, but it doesn't mean I have to follow him to what he's doing and stuff like that. And that was very useful, especially a university. (Interviewee \# 4)

Another interviewee, who received a P-DCO from Canadian students, felt they were well informed about situations involving drugs and alcohol, but they did not sufficiently understand the contexts in which these situations would occur.

During frosh week one of my [...] friends whom I met during frosh week invited me to a toga party. And you know, I had an agreement with alcohol that I don't want to drink, personal, so I did not want to drink. [...] so drinking on that day playing music, dancing, was totally different from where I came from because, although I don't drink, those who drank the drink with the knowledge that they don't want to be seen by their professors drinking, back home even if you are in fourth year, it is illegal to drink where your teachers can find you. It's like academic misconduct. So that was one. So I was there and I 
sat down with some of my professors and we were chatting. They were asking why are you not drinking and I said, "I have some personal reasons that I'm not drinking and I could take another drink but not alcohol drink." Okay, so they were fine, they were okay, [...] And then I was disturbed that night, I did not really figure out what was going on, so I had to call this lady. [...] she told me, here in Canada it's normal, [...] So at the age of freedom you can do anything you want as long as you are not doing it to violate the rights of others. Yeah that was one of the things that I found very, very different from where I came from, and it helped me to talk to and at least get to know more information.

(Interviewee \# 2)

SRP students will definitely encounter drug and alcohol use at their Canadian universities.

The interviewees expressed that relevant and useful information in the P-DCO can help them make informed choices when presented with these situations.

\subsection{Female concerns}

The one female participant I interviewed spoke of cultural competencies that were specific to the experiences of a female. The interviewee indicated that the orientation she received did not include any component addressing relevant issues that females would face upon resettlement to Canada. The participant discussed the importance of understanding differing cultural practices related to women, prior to departure. Without addressing concerns that apply specifically to females and their bodies, the interviewee felt that women SRP participants could be placed in vulnerable situations when in Canada. Some topics the participant highlighted that should be addressed in the orientation were: female medical checks, reproductive health, sexual health, women's rights in sexual activity, and women's bodies in general. The interviewee regarded knowledge of these issues as pertinent to the successful resettlement of young women, especially in the context of SRP participants and university life in Canada.

\subsection{Staying connected to life back home}

The SRP participants all come from various experiences of displacement, and maintaining connections with family and friends is very important. As a result of the initial 
isolation, participants felt there was often a strong desire to maintain frequent contact with family and friends back home. The participants discussed how they were informed, through their orientation, that they would have telephone, mail, and Internet access to stay connected. Many participants felt they were not told about the cost of these communication tools, especially the telephone.

[...] many people when they get here really want to talk to people, you really want to talk to people back home, you really want to talk to people that you know. Maybe you just want to tell them you are here already. And I just realized that many students, many refugees, they have a problem with the phone. (Interviewee \# 4)

SRP participants often encounter unexpectedly high phone bills after arrival. Although staying in touch with people back home is important, ensuring the SRP participants are aware of any foreseeable costs, or complications, may enable more effective application of the cultural competency of maintaining transnational ties, while avoiding unnecessary stress.

Also common for SRP participants is the desire to travel back home within their first few years of resettlement. It is important that participants are made aware, during their orientation, of the difficulties and costs associated with international travel.

And then the expectations, okay I'm coming to Canada alone I have friends I have a family, then maybe you think okay after a year I will go back and visit them, but sometimes you don't even think to travel, you say okay it's expensive but I think I can afford it. So sometime you say okay I'm going back but I think after a year or two I'll go back sometime. They don't think it can be difficult. (Interviewee \# 1)

If participants are more aware of the challenges of returning home, they may be better prepared for an extended time away from family and friends. Creating expectations in the PDCO can help participants to develop realistic strategies to maintain contact with family and friends back home. 


\subsection{Weather}

The weather in Canada is quite different compared to what most of the SRP participants experienced prior to arriving in Canada. All of the participants mentioned weather or climate in Canada as one of the main points in the orientation; however, not everyone was clear on the seasons and their respective months.

The perception that I had was that Canada is very cold. So I was wearing my suit, tie and gloves [...] But that was a different thing altogether, I had to remove the tie at the airport just because it was terrible. It was extremely hot and I remember it was $32^{\circ}$, hotter than Kenya where I was coming from. [...] I did it in my high school, that Canada has four seasons, the IOM said winter only so I was expecting winter. [...] I know where I came from winter is kind of different from your guys, because our winter starts in July, [...] like July to October it's the coldest part of the year and so I thought if they talk of winter that it is the same. They did not specify [...] (Interviewee \# 2)

Aside from the specific experience of this participant, most of the interviewees that spoke about weather felt they were aware of what to expect in Canada, and the appropriate clothes to wear.

\subsection{Food}

Four of the interviewees discussed issues around food at length, as they did not feel their orientation provided them with the ability to navigate the food system. Generally, the participants confirmed that they where not made aware of the diversity and availability of food products in Canada. Many of them struggled in their first few days and weeks to find food that was somewhat familiar to them. One participant was discouraged from buying food they did not recognize because they were concerned they may not like the products or that the products were inedible.

I remember I only ate one type of food and that was the food I ate for the next five days. [...] I did not want to eat anything else that I did not know. [...] I believe that was at least one aspect that I found to be missing in their cultural orientation guide. They should have, not necessarily WUSC students alone, but to anybody who immigrating to Canada that part of food should have been a vital part of the orientation. (Interviewee \# 2) 
Two of the interviewees discussed consuming products that they thought were one thing and ended up being something completely different. These experiences were discouraging for the participants, and they suggested that not being prepared to navigate the food system in Canada made them less autonomous in their choices and actions during resettlement.

Not only are the products available in Canada different from what participants may be used to, but the social practices around consuming certain products varied as well.

The food, nobody talked about the food, I can say they should have talked about the food. Nobody told me that the first week I would be starving. I went to the residence right, and they had this hamburger and salad, and I didn't eat bread with vegetables, you know like in our country you eat bread with tea or with meat, well not so much with meat, but especially bread with tea, you can't eat it at 12pm you know it's like in the morning, it's like a breakfast right? The bread I think in our country it's sweeter, but here there are many different kinds. But in residence they will give it at lunchtime and then I wouldn't be able to eat that without water especially. (Interviewee \# 5)

In most cities in Canada, people have access to a vast array of ethnic foods and restaurants. The participants expressed that they would have benefited from being informed of the different kinds of grocery stores and restaurants available to them, where they could purchase products and eat food that was familiar to them. Some participants indicated that more information about bow to order in a restaurant would have been useful to help them access food. Concurrently, one participant discussed the need for information on the cost of food. There is an abundance of low-priced food in Canadian supermarkets and restaurants, which participants may not recognize as unhealthy.

Not all participants felt that food was an issue. One participant did not seem as concerned as others about the food they were eating.

[... food actually I don't really have much to say because it depends on anybody, everybody. For me I didn't really have problems with food. I ate out of the cafeteria and whichever thing they had there I ate. (Interviewee \# 4)

Although this participant did not struggle with the food when they arrived, most of the interviewees did express concerns about food. Many participants reflected on negative 
experiences around food, that they attributed to a lack of information in the P-DCO. If SRP participants are more knowledgeable about the food in Canada they may be more likely to make healthy food choices and have a more comfortable resettlement experience.

\subsection{Commonplace in Canada}

Some of the participants acknowledged that SRP participants and other refugees who resettle to Canada may have used little electricity, or never used an oven or stove, let alone a microwave. Three participants did not feel there were concrete examples used in the P-DCO to prepare them for functioning in the day-to-day activities of life in Canada. More exposure to the cultural tools of life in Canada, prior to departure, could ease the shock of SRP participants' over-night transition, as they would have a more complete understanding of what they will see and use when they arrive.

\subsection{Life in Cities and Towns}

Three participants suggested that they could have benefited from more information regarding the city or town they were destined to. Most SRP participants do receive information from their local committees about the city or town, and university that they will be attending. However, three interviewees felt the orientation needed to provide more information to differentiate the concept of a small town in Canada compared to a small town or village in Africa. One participant suggested that SRP participants relocate from smaller towns and cities, to larger cities after their year of sponsorship because they have a perception of small towns and rural locations as places with no opportunity.

[...] in small cities there are no opportunities. Those are the things we know in Africa. Like when you live in the capital city you are somehow greater than the guy who was in the village. So when you come here nobody breaks that difference. So when they send you to a school in a small city, compared to other big cities nearby you end up to go and leave school to go to the city, just for the sake of going into the city. [...] So that is something people should just know, and it is so common in Africa because the capital city plays such a big role in the economy, and in politics, and in everything that there is so much more of 
a difference between the capital city and everywhere else. But here there is not that much of a difference, especially not in terms of schooling. Some of the best schools are in small cities and that's where you can concentrate. (Interviewee \# 5)

By including information about opportunities, and clarifying the conceptions of small towns prior to arriving in Canada, SRP participants could be more hesitant to relocate.

All of the participants said they were given general information about transportation in cities, such as buses and trains, and getting around the country. In spite of this, three interviewees felt that more city specific information, such as neighbourhoods, areas in large cities to avoid or explore, and more extensive discussion about specific city transportation systems would have been valuable.

\section{University Life}

Four of the participants had attended university in Africa and therefore, had some idea of what to expect. However, most of those participants did disclose that university in Canada was significantly different compared to what they experienced in Africa. Combined with previous experience, many participants felt prepared for the academic challenge at their Canadian university, as a result of the educational preparation they received through TOEFL and their research courses.

Five of the interviewees suggested that the P-DCO, facilitated by the IOM, did not apply to their lives at university in relation to classroom culture, academic paths, stress and academic performance, and incomplete degrees. Participants that were involved in P-DCO with Canadian students or other Canadians in the refugee camp said they were provided with useful information that prepared them for their academic experiences at university in Canada. These participants received information regarding expected class sizes, relative to their Canadian university; the approachability of university professors; and campus residences. 
Still, many participants expressed a need for more extensive preparation and information in relation to academic culture at university.

\subsection{Classroom culture}

Five participants maintained that they were not adequately prepared for their experiences in academia relating to classroom culture and conduct, group work, academic integrity, and research strategies.

On the other side, something that I did not, I was not prepared for was the mode of academic set up. Like how to, how classes are run, like here it is about a one-hour lecture and what to do before you go to a class would have been very important, if I knew it before. Like I remember my first chemistry lab, when I was in Africa [...] there was no instructor I was just given a paper, a teacher gives a practical and those were kind of an exam. [...] So when I came here I knew that I could not ask anybody about my lab, but the $T A$ 's were there, so I was wondering, if the other students were stuck at some point in their practical's they would raise their hand and ask how do I do this. [...] I had to go to the professor who is teaching chemistry. [...] and ask her about methodology and who are these guys who are standing in the room when you have a problem you raise your hand and they come over to help you. (Interviewee \#2)

[...] people are not well prepared for their education in Canada because back home people never did much research. Let's say if the professor comes today and gives you this handout, you're going to start from just this handout, you read this one and tomorrow you come for the test and you'll be okay. In Canada it's not the same, you have this handout, but you still have to go do your research, and maybe sometimes you will not even ask anything from this, that is related to this. Then when people come, they are not, let's say, very prepared. (Interviewee \# 4)

Due to the unfamiliar classroom structure, the participants encountered situations that directly affected their academic performance.

\subsection{Academic Paths}

Two of the participants indicated that they required more information about the faculty and department they were accepted into, and courses they would be taking at their universities. One interviewee discussed the need for more preparation in deciding a tentative academic path, and how possible program choices translate to likely jobs and careers in the Canadian context. 
[...] you can choose so many options but nobody tells you what is the impact of your options on jobs. [...] you know there is no career and schooling link. That again was not there. [...] In Africa you [...] you can study chemistry even though you know you will never get a job in the lab. You don't think of your career after schooling, you know you study and then you look for other things to do. That's what people know but with those options nobody tells you where to go in terms of career, so that is also a linkage that is missing. (Interviewee \# 5)

The interviewee felt quite strongly about this subject, and believed that African students need information about the link between education and career paths, as the role of higher education in Canada is not comparable to that in Africa.

\subsection{Stress and Academic Performance}

Some participants brought up the concept of stress in relation to their academic performance when they initially arrived at their university and started classes. Those that were told about notions of culture shock felt that they knew it could contribute to stress, which could impede their academic performance initially.

I learned about culture shock. They also talk about it especially in terms of academic issues, like if you come to a new place and you don't know anybody that can also have a great impact on your coursework. You may think that you are getting dumb, but in the real sense it is just part of the culture shock and a part of adjusting to the new area. (Interviewee \# 2)

Participants also discussed stressors, such as news from family and friends back home, and other challenges of resettlement, that created distractions from their schooling. The participants suggested that receiving more information about the likelihood of facing these stressors is important, so they are able to develop strategies to deal with the anticipated stress.

\subsection{Incomplete Degrees}

There were many reasons discussed in the interviews about factors contributing to SRP participants not completing their degrees. Many of the participants felt that they could have been more prepared, and aware of the circumstances they would face when ending their sponsorship. They did not feel they had the necessary cultural capital, when the time came, to 
be finically independent, allowing them to complete their studies. Although the participants are generally told about the possibility for scholarships, bursaries, and student loans, three interviewees suggested that the information was not realistic. One participant indicated that scholarships and bursaries are very competitive and often, due to the challenges of resettlement and adjustment, SRP participants will not achieve the marks required to compete for the larger amounts. The participants did not believe that these avenues of financial supplementation were adequate and that this issue needed to be tied in with money management.

I know some people who came with WUSC and they couldn't finish their studies because of their financial situation, after the sponsorship. As soon as the sponsorship is over, now there is no allowance, there is nothing. Student loans are there, but you get student loans, but they will help you maybe just pay your rent, or maybe not even. You know you still need money for food, transportation, and stuff like that. And some people are like, let me take this year off. [...] I know many people like that. But if they are well prepared here, they can finish their studies. Because most of them when they get here first year is kind of, hard they don't get a good grade, and then money also, so they are like, let me just try to work. (Interviewee \# 4)

Informing SRP participants of the necessity to prepare financially for the time following their sponsorship could alleviate a barrier to completing their studies. Students must also be made aware of the potential for accumulating debt, due to phone bills, during their first year. Many interviewees identified dealing with phone related debt as an obstacle to continuing on in their studies.

I know people who come on the program, they never finish, they racked up a whole bunch of phone bills making long-distance phone calls, because [they]'re not telling us the truth. (Interviewee \# 6)

Participants felt having more cultural competencies pertaining to financial realities, and avenues that are open to them to save and secure money for their continued education, would be a significant factor in ensuring SRP participants finish their degrees. 
Another aspect, one participant suggested, that contributes to the common occurrence of not completing studies is the lack of connection between the completion of university degrees with quality of life. The participant felt it was important to address the likely income differentiation for those who complete their degree in the P-DCO.

[...] nobody linked school with life, nobody actually tells you that school is good in Canada, because you come from countries where school is not very relevant. [...] nobody makes the link between school and quality of life from the time you leave the camp to the time you start school, you just know you're studying, but nobody tells you that school actually increases your income. I had never heard of that. [...] So many former WUSC students do not complete their degrees, so many. It's mostly because they still don't know and up to today there are so many people who actually don't know that the income difference between somebody who finishes university, [...] even if you go and work today you won't catch up, go in debt now and finish your degree. (Interviewee \# 5)

The participant believed that by associating education with opportunities later in life during the P-DCO, the SRP participants would be more inclined to stick with their degrees. Rather than leaving school all together to acquire instant income, SRP participants would be more inclined to view employment as something part-time to support their educational needs.

\section{Financial Experiences}

Financial issues were addressed by the participants, while speaking about many of the previous themes. However, there are components that do apply specifically to finances that participants mentioned. Elements of money and finances are covered in the P-DCO, but the interviewees discussed topics that they indicated were not adequately addressed in the orientation, and that they were not prepared for upon arrival. Participants felt some financial topics mentioned in the P-DCO did not effectively develop appropriate cultural competencies needed, in turn creating unrealistic expectations, which at times had negative implications.

\subsection{Financial Expectations}

Each participant comes from a different financial situation, and may have little to no experience with money or finance. Most participants did not feel that they understood their 
finances, and worried about their money and budgeting prior to arrival. Because SRP participants are sponsored by different universities, they experience slightly different financial structures. However, from their pre-departure knowledge, all the participants expected to have access to money upon arrival, so they could begin settling, and obtaining essential needs. A participant spoke about the negative implications of this expectation when they did not receive any monies during the first two weeks in Canada. The interviewee ended up relying on another SRP participant who had come the year prior.

During that week my friend, we had to be 2 person on one person's budget, so it was very hard because actually I had certain things I didn't have [...] like soap. [...] The income issue was a bit hard to actually, because they told me that I will have money and a bank account but I didn't have them when I was there in the first two weeks, so that was something also which, I was expecting it. (Interviewee \# 5)

Including information in the P-DCO about the potential for scenarios like this to occur, will help SRP participants better prepare for the reality of difficult financial situations that may arise during resettlement.

Five of the interviewees believed they did not understand the value of currency in Canada because examples given in their P-DCO were not relevant to their previous experiences with finance. Though participants were generally told how much money they would receive, they felt as though they did not understand what the money amounts meant. One interviewee discussed how they were told they would have one hundred dollars to spend monthly, but they were not aware of all of the expenses they would have as a student.

[...] why would I think that $\$ 100$ is not a lot of money, they don't know who is responsible for that. I guess nobody speaks about the money, that it ends up being on the student as if, okay they told me that I will have money but how much money, and is it enough? (Interviewee \# 5)

It is important that participants are not only given meaningful examples of currency denominations, but that they are provided with a realistic understanding of their expenses. 
Participants were also told about credit, and credit cards, in the P-DCO, and how to handle money in Canada. They felt these concepts were valuable to know, as many of them were not familiar with the plastic debit cards and credit cards.

So the things that I didn't, that I was not used to doing, like shopping, like how you handle money [...] They said, of course in Africa, we carry a lot of cash with us. You will be carrying a card, which is a plastic thing that you will be swiping somewhere and then that's how you will be paying for things. (Interviewee \# 3 )

I really had no idea about the money issue. I didn't know how I would be carrying the cash in my pocket, like it was very - I actually didn't know (Interviewee \# 5)

Although the information pertaining to credit and debt was applicable to their experiences, one participant felt that the P-DCO provided an inaccurate understanding of credit.

They say it's not good, its debt, but they don't link it with future life like building credit. They say that the credit is, the credit you have to pay it back, but they don't say that the credit report is something, which goes towards buying a house. [...] Nobody actually made that link. (Interviewee \# 5)

Many of the participants spoke about how the P-DCO could have done more to discuss how financial actions during resettlement, such as building credit, can have future implications during resettlement and integration in Canada.

Three of the interviewees commented on the difficulties of financing education after the sponsorship period. They felt that the P-DCO needs to do more to create the expectation that participants will have to save money when planning to continue in their studies.

[...] when they come here some of them will go to school, you get sponsored a year, or maybe four years. Then after that you are on your own. I think what they could focus on more again, would be how to save, how to save money. [...] from where they're coming from and stuff like that, they don't have the, what can I say, the knowledge of saving. Then after the sponsorship is over, you say oh well I had money, like a couple of months ago, what did I do with the money? Then life kind of starts, you're starting again life from zero [...] And I think in the like the WUSC program, especially the WUSC program, that should be one of the key points, when preparing someone. (Interviewee \# 4) 
Providing SRP participants with competencies that anticipate their financial needs for the months, and years ahead can create a more balanced adjustment to university and later integration into life in Canada.

\subsection{Budgeting}

The participants said they received general information prior to their departure about budgeting and that it was useful, but they maintained that some issues came up after arrival that they were not prepared for. Because many SRP participants are not familiar with Canadian currency, cost of living, and the materiality of Canadian culture, some of the interviewees felt they struggled to stay within their budget. The participants reflected experiences with their budgets and the difficulty of balancing their needs with their financial realities:

[...] when you are coming they are talking about clothing but you are coming from a refugee camp and nobody actually buys these clothes to be ready in the first place, [..] So that means when you come here you have your own clothing, which is not maybe suitable for the environment. (Interviewee \# 5)

And the budget on food too because people tend to reduce things, but if you make too much budget on your food your health is kind of compromised, so they have also to know that you can save, but don't save on food. (Interviewee \# 5)

I just realized that many students, many refugees, they have a problem with the phone, the phone. Because I think I know more than three people who after being here for just one month, they ended up paying a phone for maybe 2000 and, 1000 dollars, because of long distance [...] when the bill comes, then the local committee has to figure out what to do sometimes, see what I mean? So if people can get prepared for that too. (Interviewee \# 4)

Four participants emphasized that money and budgeting contributed significantly to the challenges of resettlement. The participants suggested that much of what they learned about finances was through their experiences after arrival and if they had been given more information and strategies in the P-DCO, budgeting may not have been so difficult. 


\subsection{Remittance}

The practice of sending remittances to family and friends back home is common for refugees and other immigrants, and two of the SRP participants felt that it was not appropriately discussed in the P-DCO. One participant spoke of how they were told not to expect to be able to send remittances, as it was not in their budget. However, some of the participants discussed the expectation and pressure from those back home to send money, and most participants do want to help those back home

\subsection{Employment}

On the topic of employment, most participants cited being told in their orientation that they would be eligible to work in Canada as landed immigrants, but they felt more extensive information pertaining to employment in Canada would have been beneficial. Two interviewees stated they had been told in the P-DCO about part-time jobs, and the possibility to earn money to supplement their monthly sponsorship income. Interviewees explained that employment information was important because they felt getting jobs could allow them to save money for after their sponsorship and send remittances home. Participants highlighted the need for a more comprehensive understanding of the tools required to navigate the Canadian employment process, such as how to apply for jobs, and how to prepare for interviews.

About employment, actually employment nobody, it's very little, like employment nobody plans, even from the IOM and WUSC, nobody had an idea about employment issues. (Interviewee \# 5)

More specifically, this interviewee discussed understanding elements of the Canadian employment process, such as the concept of references. The interviewee said: "Like references, in our country there are no references." (Interviewee \# 5). They expressed that the practice of providing a reference was something they were not familiar with, not only when applying for jobs, but also when applying to rent an apartment. 


\section{Laws and Rights}

Although interviewees did not discuss laws and rights in Canada extensively, they felt, for the most part, that the P-DCO left them well prepared in this area. Because the SRP participants often come from diverse socio-cultural backgrounds, emphasizing Canadian laws and rights prior to departure is important. Participants must be aware of their standing within the laws, and how they relate to them, so they can function and participate in Canadian society. Similarly, the P-DCO helped to inform the participants on how to access services related to the laws and rights.

[the orientation] helped some of us to identify or to understand, especially some of the basic rules and safety. Like the fire alarm, like how to get to a hospital when you are sick. Like when you have any trouble, how to call 911 . At least those were practical to me, those were practical, and I really need them [...] (Interviewee \# 2)

I don't think we even have a number you just contact the police and report your problem, you know, you don't call. (Interviewee \# 1)

The practicality of information pertaining to safety procedures enabled the interviewees to be aware of the different public safety services available to them, and how to access emergency help if necessary.

\subsection{Rights and Freedoms}

Having information about their rights and freedoms seemed important to the participants, as circumstances in Canada are different from what many of the participants had experienced before. All the interviewees indicated that they were informed about their rights and freedoms, and the rights of others in Canada during the P-DCO.

So they are just trying to tell us the difference in Canada and some of the countries in Africa. Like in Canada, nobody can just arrest you when you have everything, all the documents with you and stuff like that, when you haven't done anything, just remember that part of the orientation. (Interviewee \# 4)

The interviewees valued the knowledge they were given surrounding interactions with authorities, like the police. 


\subsection{Sexual Harassment, Discrimination and Racism}

Concepts of sexual harassment, discrimination, and racism in the Canadian context can be new for some SRP participants, and are thus, hard to navigate. Interviewees indicated that these were important topics to be informed about during the P-DCO. One participant felt as though more discussion could have occurred around what constitutes sexual harassment in comparison to socio-cultural practices that are considered acceptable in the culture that they came from.

While the participants specified that they were given information about diversity and multiculturalism in Canada, some indicated that they would have benefited from a more realistic perspective on the potential to experience racism and discrimination.

I think certainly the whole discrimination thing and of course they can't be explained for every situation, but just highlight that it does exist and people will relate to you based on, you know your background or your skin color, or people act different to you based on that. (Interviewee \# 6)

Being more cognizant of the reality of racism and discrimination was something the SRP participants identified as a competency they needed.

There is something, which is big, and as I can remember no one told us about, [...] You can find racism in small towns and, and sometimes because, some people don't, okay some people know that you can have experience with some kind of racism in Canada or USA, but some of the students don't know what should I, how would I know someone is racist or is not? (Interviewee \# 1)

Discrimination and racism does take place in Canada, and being aware of the circumstances where it might occur was relevant to the participants.

Conversely, one interviewee mentioned how the orientation needed to address situations where SRP participants could be perceived as being discriminatory or racist themselves. The participant used the example of homosexuality in Canada, pointing out that many SRP participants were socialized in environments where homosexuality is not accepted, 
and in many cases it is considered illegal. If SRP participants are not explicitly made aware of the rights of the gay community within Canada, they themselves may unknowingly partake in acts of discrimination. Clearly, issues surrounding discrimination and racism can be contentious, however they are important topics that should be addressed, in order to ensure SRP participants are conscious of the possibility of being discriminated against, or discriminating against others.

\section{Discussion and Recommendations}

This study revealed the overall nature of the Pre-Departure Cultural Orientation ( $P$ DCO) that the Student Refugee Program (SRP) participants receive, as an avenue for acquiring the cultural competencies to successfully participate in Canadian culture upon arrival. Although there are inconsistencies between the orientations received by participants, they described the information provided during their orientation as generally applicable to their resettlement experience. By encouraging the development of cultural resources and knowledge prior to migration, the P-DCO contributed to reducing the stresses and challenges faced during resettlement (Stewart et al, 2008). Through their stated unfamiliarity with Canada, and Canadian culture, prior to commencing the orientation, participants demonstrated that they required the cultural capital they received. The participants found their experiences during resettlement perceivably relevant to what they engaged with during the orientation. Through exposure to selected cultural capital in the P-DCO, the responses suggest the participants were noticeably prepared to navigate through some of the cultural uncertainty.

The orientation did function to lower the participants' expectations pertaining to their anticipated resettlement experiences (Stewart et al, 2008; McLean, Friesen \& Hyndman, 2006; Simich, Hamilton \& Baya, 2006). However, all of the participants did indicate they felt they 
were mislead at times, as some of the cultural competencies discussed in their orientation were not fully developed or were irrelevant to their resettlement. The participants expressed that the orientation did not effectively deliver all of the necessary and appropriate cultural capital, which contributed to some of the challenges they encountered during resettlement. Moreover, the participants comments demonstrated that the cultural competencies in the P-DCO were limited, and lacked depth to coincide with the extent of experiences faced during their adjustment period. Limiting knowledge and resources about new cultural practice will likely hinder ones ability to function within the new culture (Bourdieu, 1973). Consistent with research in the field of international students, without appropriate cultural preparation SRP participants' experienced negative implications associated with their schoolwork, in tum impeding their academic success (Ward, Bochner, \& Furnham, 2003; Martin, 1989).

Despite acknowledgment by all the participants that they were able to draw on resources and cultural competencies conveyed through their orientation, the findings speak to the necessity for the orientation to engage with knowledge and information that surpasses initial resettlement issues. Participants believed that they learned much of what was left out of the P-DCO while adjusting and settling in Canada. Participants discussed challenges in dealing with the cultural competencies included in the cultural capital categories established in Table $1(\mathrm{p} .20)$. The findings suggest that the cultural competencies required in socio-cultural experiences were not sufficiently delivered, such as the ability to navigate isolation, engage with Canadians, resolve gender related interactions, and engage with the food system. Moreover, five participants expressed difficulties in applying the cultural competencies required in university and education. Each participant drew on obstacles faced at university, demonstrating they were not efficiently prepared with the cultural capital to navigate the Canadian university system. In the context of financial experiences, five of the six 
participants expressed substantial challenges in their ability to manage and understand the Canadian financial system and their personal finances. Similarly, four participants did not feel adequately prepared to engage with the Canadian employment process. Those participants who mentioned the cultural competencies relative to laws and rights indicated that the competency of understanding personal rights was generally brought forth. However, most participants did not consider their ability to deal with and understand racism, discrimination, and appropriate gender interaction to be strong enough to successfully navigate within Canada.

Even though most of the cultural competencies required for successful resettlement are addressed in the combination of the International Organization for Migration (IOM) and the World University Services of Canada (WUSC) orientations, the participants maintained that the cultural capital they received was not consistent or extensive enough to effectively prepare them for resettlement. This finding complements research by McLean, Friesen \& Hyndman (2006), Stewart et al (2008), and the IOM (2004), which reveal the need for consistent, relevant information to be provided prior to departure that is appropriately developed to coincide with the needs of the refugee group receiving the information. In this study, evidence presented through the interpretation of participants' experiences suggests that orientation reform is required. The P-DCO needs to more effectively convey and apply the necessary cultural competencies to establish appropriate cultural capital for SRP participants' resettlement and integration.

The findings also reveal that the two participants, who received longer orientations, or a combination of orientations from sources other than the IOM, expressed feeling more prepared when utilizing the cultural competencies in Canada and at their university. The participants who did not receive an extensive orientation session emphasized that they did not 
feel adequately prepared when navigating in Canadian culture. As is stated by Bourdieu $(1973,1986)$, the more time that is invested in acquiring the cultural competencies, the more cultural capital an individual will have at their dispense, mitigating the challenges and barriers to fully participate in society. This point is echoed by Citizenship and Immigration Canada (2005a), as the length of time that an orientation is provided contributes to the quality and amount of resources that can be imparted on those receiving the orientation. The more time allotted to facilitate the orientation, the more effective the orientation will be at transmitting cultural capital to the participants, and encouraging their successful resettlement.

Another significant finding that emerged from the data is the importance of connecting with Canadians, especially Canadian students, prior to departure as a valuable orientation facilitation method. The participant who received an orientation with Canadian students, and those who had the opportunity to interact with Canadians prior to their departure, valued that experience and expressed that it enabled them to get a better understanding of Canadian youth and university culture. Face-to-face engagement with Canadians provided an effective delivery of cultural capital, as the participants who received this opportunity expressed confidence in applying many of the cultural competencies once in Canada. Similarly, all participants viewed the contact with their local committees as meaningful. The contact provided them with a more clear idea of what, and who to expect when they arrived at their university. The participants indicated that the creation of social networks, through contact with their local committees, emphasized feelings of preparedness, and that they were a valuable resource during resettlement. This finding also suggests that the development of social capital or social networks prior to departure contributes to successful resettlement and adjustment as supported by the research of Kunz (2005). The propensity for social capital to mollify resettlement stress and challenges, while encouraging feelings of connection and 
belonging, has been shown to contribute to successful resettlement of other refugee groups (McLean, Friesen \& Hyndman, 2006; Simich, Beiser \& Mawani, 2003; Suzuki, 2005).

\section{Recommendations}

In examining the findings, some recommendations arise related to the P-DCO that the SRP participants receive. As the participants maintained, they required more relevant cultural capital in the P-DCO in order for them to feel adequately prepared. They indicated that after experiencing life in Canada, the topics and issues they discussed where lacking in the P-DCO. The interviewees believe that future SRP participants would benefit from the information and knowledge, which they brought forth. Therefore WUSC should attempt to engage with more rigorous assessments of past SRP participants' experiences regarding their P-DCO and resettlement. In doing so, WUSC can extract information that can be applied to the future development of their P-DCO in connection with the IOM orientation.

Beyond the information that is covered in the P-DCO, the participants spoke about the desire for a longer orientation. A longer orientation period would allow for reflection on the topics covered and for an opportunity to develop and address questions. An increased orientation period could be achieved through the development and implementation of a curriculum alongside the academic preparation the participants receive in the year prior to migration.

Finally, the participants who were able to interact face-to-face with Canadians, and Canadian students prior to departure, benefited significantly from the experience. There is a need for WUSC to seek avenues so SRP participants can connect with Canadian students in person prior to departure. I am aware that the resources available to create such opportunities are limited. WUSC could explore employing the same framework used in their Students Without Borders program, where Canadian students pay their own way to volunteer abroad 
and receive university credit. A similar strategy in the SRP could decrease the cost to WUSC and enable valuable student-to-student interaction between Canadians and SRP participants.

\section{Areas for Future Research}

This study, though small in size, has lead to a wealth of information that addresses some of the shortcomings in the current literature, while opening up areas where future research is required. From the perspective of methodology, a larger sample size is required to better encapsulate the experiences and issues that Student Refugee Program (SRP) participants encounter during their pre-migration and resettlement. Collecting more participants' perspectives and input would increase the understanding of SRP participants' experiences with the Pre-Departure Cultural Orientation (P-DCO) and resettlement. Understanding a wider range of SRP resettlement experiences relative to P-DCO would allow for more in-depth exploration of specific issues, especially around female concerns and gender analysis. A more focused study that explores the methods of facilitation used both by World University Services of Canada (WUSC) and the International Organization for Migration (IOM) in P-DCO for $\mathrm{SRP}$ participants is also necessary. By examining the methods used in the inculcation of information, appropriate and comprehensive strategies may emerge. Effective methods can then be implemented to facilitate valuable P-DCO for SRP participants.

Future research focusing on specific P-DCO delivery methods related to individual cultural competencies would be an efficient research method to measure the effectiveness of P-DCO for SRP participants. As well, research concentrating on the experiences of specific SRP cohorts would contribute to a more balanced assessment of SRP participants' application of the competencies developed in their orientations. The delivery of each competency during the P-DCO, and the necessity of each competency after arrival, will impact individual 
participants differently. Research that looks at specific competencies, facilitation methods, and cohorts will produce more relevant comparisons of SRP participants' experiences with PDCO.

Although this study was designed to examine the role of $\mathrm{P}-\mathrm{DCO}$, an unexpected issue faced by SRP participants was uncovered that requires a further research investigation. Many of the participants spoke about the reality of incomplete degrees and the factors they felt contributed to this outcome. Despite my attempt to expose this issue in the context of this research initiative, a focused study is needed to further examine the complexity of this reality for SRP participants. How many SRP participants are unable to complete their degrees due to their financial situations? Are there other factors present that could be addressed prior to departure to prevent this from happening in future cohorts? Through establishing documentation of the frequency and prevalence of incomplete degrees, WUSC could attempt to mitigate the contributing circumstances that the SRP students face.

\section{Conclusion}

This research sought to document and engage solely with the role of Pre-Departure Cultural Orientation ( $\mathrm{P}-\mathrm{DCO})$, and explore how this aspect of a resettlement strategy functions for those who experience it. The Student Refugee Program (SRP) participants demonstrated that the P-DCO they received was a valuable tool in their migration journeys. It contributed to the development of expectations, though not always realistic, shaping their resettlement experiences in Canada and at their universities. The P-DCO provided the participants with a general overview of the cultural competencies required to obtain the cultural capital necessary for their resettlement and integration. Through face-to-face interaction with Canadians and Canadian students, or communication with their World University Services of Canada 
(WUSC) local committees, the participants were able to establish social networks during their P-DCO that were valuable in facilitating resettlement. These social networks also encouraged the development of cultural capital, creating a domain to apply some of the cultural competencies prior to departure. However, the findings contend that the P-DCO was not effective in delivering the entirety of cultural competencies and cultural capital required for the SRP participants to feel adequately prepared during resettlement and throughout integration.

Considering that this is one of few academic studies to date which examines the role of pre-departure preparation, the voices of the SRP participants establish a strong base to review the issues that are most relevant to the current structure of P-DCO. The findings that emerged in this study reinforce the need for WUSC to further engage with the SRP participants to address issues and incorporate them in future P-DCO. As WUSC continues to create opportunities for successful resettlement linked with education, the participants' input, generated by their lived experiences, provides valuable information to understand premigration preparation. Given that the Canadian government remains committed to exploring ways to improve migration experiences to Canada, this study may also provide useful information in the development of future policies pertaining to newcomer migration and settlement strategies.

The evidence flowing from this research confirms the need for further empirical research on the role of $\mathrm{P}-\mathrm{DCO}$, not only for SRP participants, but other refugee and immigrant groups to Canada as well. P-DCO is a mechanism that aids the participants' process of transition and resettlement, giving them an opportunity to develop some degree of cultural capital. This research, combined with the reviewed literature, demonstrates that developing cultural and social capital, prior to migration, can function to alleviate stress and contribute to 
success during the resettlement process. It is important to consider that no amount of orientation can completely prepare people for experiences they have not yet had, but providing accurate, relevant, and comprehensive information in P-DCO can provide participants of the SRP with the cultural and social capital they need for their lives in Canada and at university. 
Appendix A

Ryerson University

Immigration and Settlement Studies Master Program

\section{Do you know current or past participants of the WUSC Student Refugee Program, who want to volunteer for a research study?}

\section{What to Expect? Examining the Role of Pre-departure Cultural Orientations}

The purpose of this research is to explore whether the content that is provided in the predeparture cultural orientation that students in the Student Refugee Program receive prior to arriving in Canada is relevant to their experiences after landing in Canada.

Eligible voluntary participants must be Student Refugee Program participants' who participated in the Student Refugee Program after 1998 and received a pre-departure cultural orientation prior to departure to Canada. Those interested must be able to committee to a 2-

hour interview sometime during the month of June 2009. Those people who chose to participate identity will be kept confidential.

The benefits to this research is that it may lead to development of an up-to-date, and student specific, pre-departure cultural orientation for future students in the Student Refugee Program to better prepare them for their arrival in Canada.

The interviews will take place on Ryerson University Campus in a private location. Those who do choose to participate in this research identity will be kept confidential and will not be identifiable to WUSC or the SRP.

To learn more about this research or if you are interested in participating or know someone who is interested in participating, call Ashley Korn at:

$$
416-792-3594
$$

\section{Or by email: ashley.korn@ryerson.ca}

This research is conducted under the direction of Grace-Edward Galabuzi, Associate Professor in the Politics and Public Administration Department at Ryerson University 


\section{Appendix B}

\section{Intake form}

What to Expect? Examining the role of pre-departure cultural orientation

Name

What is your first language?

What is your country of origin?

When did you come to Canada?

What University do/did you go to in Canada?

What is/was your major or focus of study? 


\section{Appendix C}

\section{Questions/Prompts for SRP participant interviews}

1. How did you end up being selected for the SRP, what was the process like?

2. What was your perception of Canada prior to the orientation, what did you already know?

3. Before leaving for Canada, did you receive a cultural orientation about life in Canada?

4. Can you tell me about the information you learned/were provided with in the cultural orientation?

Could you tell me a bit more about ?

5. Who facilitated the cultural orientation?

6. Did this mode of facilitation work for you?

What were the strengths and weaknesses, what worked for you and what did not?

7. In reflecting on your experiences during the time you received the pre-departure cultural orientation, did you feel prepared after the cultural orientation for your anticipated transition to life in Canada?

And after you arrived in Canada did you feel the same way?

8. When you arrived in Canada did you feel prepared for what you experienced?

Could you give me some examples?

9. Given your experience with the pre-departure cultural orientation, can you tell me about your experiences when you arrived in Canada for the first time?

Could you tell me a bit more about ?

10. How did the pre-departure cultural orientation apply to the experiences you had with university life?

Did it prepare you for what you experienced in university?

Can you tell me more about ?

11. What information do you wish you knew prior to arriving in Canada and at your university, that you did not know?

What information do you think should be included that would be would be helpful to know in the cultural orientation that was not provided to you, that may ease the settlement of future students?

Money/finances; Food; Health Care; The university; The town/city you were relocating to; Employment; Social life (pre-contact with a mentor?); Visuals or roll playing.

12. Did any of the information you received in the cultural orientation construct false expectations or ideas in comparison to what you experienced when you arrived? 


\section{Questions/prompts for SRP administration staff}

1. How long has the pre-departure orientation been in practice for?

2. Why was the P-DCO developed?

3. What are the expected goals/outcomes of the P-DCO?

4. How is the P-DCO administered?

5. How is the P-DCO evaluated?

6. What is the policy framework that the SRP and the pre-departure cultural orientation are developed from?

7. Can you tell me your thoughts on the pre-departure cultural orientation that the SRP participants receive?

Could you expand on $?$

8. Do you think the information that is provided is sufficient in preparing them for their experiences, generally and more specifically in university, once they arrive in Canada?

In what way?

9. From your perspective, do you think the participants feel adequately prepared for their resettlement process once in Canada, prior to departure?

Could you explain in more detail?

10. What do you think should be included in the pre-departure cultural orientation that is not?

Do you think this information could potentially improve the SRP participant's experiences?

11. Do you think the participants who received the pre-departure cultural orientation are adequately prepared for what they will experiences in comparison to those who may not have received an orientation in the past? How? 


\section{References}

Beiser, M., \& Hou, F. (2001). Language Acquisition, unemployment and depressive disorder among southeast Asian refugees: a 10-year study. Social Science \& Medicine, 53 (10), $1321-1335$.

Biles, J. (2008). Integration Policies in English Speaking Canada. IN Immigration and Integration in Canada in the Twenty-first Century. Bile, J., Burstein, M., \& Frideres, J. (Eds). Montreal: School of Policy Studies, Queen's University.

Bourdieu, P. (1973). Cultural Reproduction and Social Reproduction. IN Brown, R. (Ed). Knowledge, Education and Cultural Change : Papers in the Sociology of Education. USA: Harper and Row Productions, Inc.

Bourdieu, P. (1986). The Forms of Capital. IN Richardson, J. G. (Ed). Handbook of Theory and Research of the Sociology of Education. New York: Greenwood Press.

Canadian Council for Refugees. (2003). Comments on Settlement and Integration to the Standing Committee on Citizenship and Immigration. Retrieved on February 19, 2009 from the World Wide Web: http://www.ccrweb.ca/settlementcomments.html.

Citizenship and Immigration Canada. (2005a). Report on the Evaluation of the Delivery of the Canadian Orientation Abroad Initiative. Retrieved on February 19, 2009 from the World Wide Web: http://www.cic.gc.ca/english/resources/evaluation/orientation.asp.

Citizenship and Immigration Canada. (2005b). Report on the Evaluation of Canada's Membership in the International Organization for Migration. Retrieve on February 19, 2009 from the World Wide Web:

http://www.cic.gc.ca/english/resources/evaluation/loM/eval find.asp.

Citizenship and Immigration Canada. (2008). Facts and Figures 2008. Retrieved on August 7, 2009 from the World Wide Web:

http:/www.cic.gc.ca/english/resources/statistics/facts2008/permanent/01.asp

Courtney, L. J. (2007). Voices on Education in Protracted Refugee Situations: Reflections and Recommendations of Sudanese Refugees. Masters of International Comparative Educations, Stanford University.

George, U. (2002). A Needs-based Model for Settlement Service Delivery for Newcomers to Canada. International Social Work, 45 (4).

Horst. C. (2006). Buufis amongst Somalis in Dadaab: The Transnational and Historical Logics behind Resettlement Dreams. Journal of Refugee Studies, 19 (2), 143 - 157.

International Organization for Migration. (2005). Pre-departure Orientation/Cultural Orientation. Retrieved on February 19, 2009 from the World Wide Web: http://www.iom.int/jahia/webdav/site/myjahiasite/shared/shared/mainsite/published do cs/brochures and info sheets/pre departure.pdf.

Jackson, J. (2004). Language and Cultural Immersion: An Ethnographic Case Study. Regional Language Centre Journal, 35, (3), 261-278.

Kilbride, K. M., Anisef, P., Baichman-Anisef, E., and Khattar, Randa. (2001). Between two Worlds: The experiences and Concerns of Immigrant youth in Ontario. CERIS. 
Kunz, J. L. (2005). Orienting Newcomers to Canadian Society: Social Capital and Settlement. IN Policy Research Initiative. Social Capital in Action: Thematic Policy Studies.

Lamba, N. K. (2003). The Employment Experiences of Canadian Refugees: Measuring the Impact of Human Social Capital on Quality of Employment. Canadian Review of Sociology \& Anthropology, 40 (1), 45-64.

Li, P. (2003). Destination Canada: Immigration Debates and Issues. Toronto: Oxford University Press.

Locke, L. F., Liverman, S. J., \& Wyrick Spirduso, W. (2004). Reading and Understanding Research $-2^{\text {nd }}$ Edition. Thousand Oaks: Sage Publications: International Education and Professional Publisher.

Martin, J. N. (1989). Pre-departure Orientation: Preparing College Sojourners for Intercultural Interaction. Communication Education, 38, 249-258.

McLean, J., Friesen, C., \& Hyndman, J. (2006). The First 365 Days: Acehnese Refugees in Vancouver, British Columbia. CERIS Working Paper Series.

Merriam, S. (2002). Introduction to Qualitative Research. Qualitative Research in Practice. San Francisco: Jossey-Bass.

Murdie, R. A. (2003). Housing Affordability and Toronto 's Rental Market: Perspectives from the Housing Careers of Jamaican, Polish and Somali Newcomers. Housing, Theory and Society, 20 (4), 183-194.

Neuman, W. L. (2006). Social Research Methods: Qualitative and Quantitative Approaches$6^{\text {th }}$ Edition. Toronto: Pearson/Allyn and Bacon.

Portes, A. (1998). Social Capital: Its Origins and Applications in Modern Sociology. Anmual Review of Sociology, 24 (1).

Ramsey, P., Ramsey, D., \& Mason, R. (2007). The Massey Kiwi Friend Program. Innovations in Education and Teaching International, 44 (2), 109-188.

Simich, L., Beiser, M., \& Mawani, F. N. (2003). Social Support and the Significance of Shared Experience in Refugee Migration and Resettlement. Western Journal of Nursing Research, 25 (7), 872-891.

Simich, L., Hamilton, H., \& Baya, K. B. (2006). Mental Distress, Economic Hardship and Expectations of Life in Canada among Sudanese Newcomers. Transcultural Psychiatry, $43(3)$.

Stewart, M., Anderson, J., Beiser, M., Mwakarimbas. E., Neufel, A., Simich, L., and Spitzer, D. (2008). Multicultural Meanings of Social Support Among Immigrants and Refugees, International Migration, 46 (3), p. 123 - 157.

Suzuki, R. (2005). Social Capital and the Significance of Pre-migration Context Among Burmese Refugee Communities in Canada. CERIS Working Paper Series, No. 36.

Torres, K. (2009). 'Culture Shock': Black Students Account for Their Distinctiveness at an Elite College. Ethnic and Racial Studies, 32 (5), 883-905.

United Nations High Commission for Refugees. (2004). Supporting Next Steps in Integration Initiatives: An Inventory of Opportunities and Needs in the Integration of Resettled 
Refugees. Retrieved on February 19, 2009 from the World Wide Web: http://www.unhcr.org/protect/PROTECTION/4173839e4.pdf.

Valtonen, K. (1999). The Societal Participation of Vietnamese Refugees: Case Studies in Finland and Canada. Journal of Ethnic and Migration Studies, 25 (3), 469-492.

Ward, C., Bochner, S., \& Furnham, A. (2003). The Psychology of Culture Shock $2^{\text {nd }}$ Edition. New York: Routledge.

Wilkinson, L. (2008). Labour Market Transitions of Immigrant-Born, Refugee-Born, and Canadian-Born Youth. Canadian Review of Sociology, 45 (2).

WUSC. (2007a). Fostering Tomorrow's Global Leaders: An Evaluation of the WUSC student Refugee Program. Ottawa: World University Service of Canada.

WUSC. (2007b). Pre-departure Guide for WUSC Sponsored Students: Almost Everything You Wanted to Know about Living and Learning in Canada, but were afraid to Ask. Ottawa: World University Service of Canada.

Yu, S., Ouellet, E., \& Warmington, A. (2007). Refugee Integration in Canada: A Survey of Empirical Evidence and Existing Services. (Report). Refugee, 24.4.

Ying, Y. (2002). Formation of Cross-Cultural Relationships of Taiwanese International Students in the United States. Journal of Community Psychology, 3(1), 45-55. 